Revue d'histoire de l'Amérique française

RS REVUE D.HISTOIRE DE L'AMÉRIQUE FRANÇAISE

\title{
La sauvegarde des patrimoines dans le district de Québec durant la première moitié du $\mathrm{XIX}^{\mathrm{e}}$ siècle
}

\section{Fernand Ouellet}

Volume 26, numéro 3, décembre 1972

URI : https://id.erudit.org/iderudit/303192ar

DOI : https://doi.org/10.7202/303192ar

Aller au sommaire du numéro

Éditeur(s)

Institut d'histoire de l'Amérique française

ISSN

0035-2357 (imprimé)

1492-1383 (numérique)

Découvrir la revue

Citer cet article

Ouellet, F. (1972). La sauvegarde des patrimoines dans le district de Québec durant la première moitié du $\mathrm{XIX}^{\mathrm{e}}$ siècle. Revue d'histoire de l'Amérique française, 26(3), 319-374. https://doi.org/10.7202/303192ar d'utilisation que vous pouvez consulter en ligne. 


\title{
LA SAUVEGARDE DES PATRIMOINES DANS LE DISTRICT DE QUÉBEC DURANT LA PREMIẼRE MOITIÉ DU XIX SIECCLE
}

\author{
Fernand Ouellet \\ Carleton University \\ Ottawa
}

Les pratiques successorales, à cause de leurs implications économiques et sociales, constituent un important sujet de recherche. Ainsi la Coutume de Paris stipulait le partage égal des biens roturiers entre les héritiers. De ce fait elle introduisait dans la vallée du Saint-Laurent le principe de la désintégration des fortunes bourgeoises et paysannes et, surtout, de la propriété foncière. Au lendemain de 1760, Francis Masères qui avait pu observer les conséquences du droit successoral, écrivait: "La seule chose qui me parût manquer à ce système admirable (le régime seigneurial), c'est un principe qui dût le rendre permanent. Mais là il me sembloit que le gouvernement François avoit agi d'une manière inconséquente, et presque comme s'il avoit tasché de renverser son propre ouvrage. Car au lieu d'établir comme loi fondamentale, nécessaire à la conservation de ce système, l'indivisibilité des seigneuries et des terres en censive concédées par les seigneurs aux paysans, afin de maintenir deux classćs de personnes dans leur état primitif... il établit au contraire une loi de succession aux terres par partage entre co-héritiers, qui devoit bientôt tout renverser, et réduire toutes les concessions, même les seigneuries, à de simples arpens quarrés... ${ }^{1 "}$ Cette critique de Masères, qui semble partisan de la primogéniture, s'inspirait d'une tradition centrée sur le maintien de l'intégrité des patrimoines. Dans cette perspective, la primogéniture avait comme fonction d'assurer à la fois la stabilité sociale et la survie des unités de production. Bien entendu, une telle tradition, par l'intérêt qu'elle porte à la propriété, favorise aussi l'agrandissement des patrimoines. Les efforts de Masères pour obtenir une réforme des lois successorales soulevèrent de fortes objections de la part du juriste Cugnet qui parla de "justice naturelle" et du droit égal des enfants à l'héritage paternel. La tradition que portait et défendait Cugnet en appelait d'abord

1 Cité par Pierre Tousignant, La genèse et l'avènement de la Constitution de 1791. Thèse de doctorat (Université de Montréal, 1971), 136.

RHAF, vol. 26, no 3 (décembre 1972) 
à l'affection égale que le père devait à ses enfants. Ainsi fondé, le partage des biens devenait une nécessité morale, même si la fragmentation aboutissait à créer des exploitations trop petites pour faire vivre une famille.

Si le partage des biens entre les descendants avait nécessairement abouti au morcellement des terres à chaque génération, il est bien évident que la situation serait vite devenue tragique. Mais, jusqu'à la fin du XVIII e siècle, l'abondance des terres dans la plupart des régions du Québec empêche une fragmentation trop rapide des tenures. Dans ce contexte où les seigneurs avaient encore intérêt à concéder sur demande et gratuitement, il était alors relativement facile pour un paysan d'établir ses fils dans le voisinage. On peut même supposer qu'à cette époque la pratique de "se donner" de son vivant à l'un des héritiers mâles était plutôt répandue. En tout cas elle ne portait pas atteinte aux intérêts des autres membres de la famille. Il faut dire que de nombreux gros cultivateurs, désireux de conserver intègre le patrimoine, possédaient les fonds nécessaires pour établir les autres enfants. Par contre l'apparition du phénomène de la rareté des terres incitait à la subdivision des tenures selon les termes de la Coutume de Paris. Ainsi, surtout après le début $\mathrm{du} \mathrm{XIX}^{\mathrm{e}}$ siècle, la pénurie croissante de terres dans les seigneuries et les pratiques restrictives des seigneurs, tout autant que le régime juridique, favorisent le morcellement de la terre. Dans quelle mesure les paysans pourront-ils résister à cette pression?

Il est certain que dans le district de Montréal, là où le sol était le plus riche, la paysannerie a été incapable ou a refusé par fidélité à une tradition de mettre un frein au démembrement progressif des patrimoines. Le recencement de 1831 fait état de cette situation qui allait en se détériorant. Quelques exemples illustrent assez bien ce phénomène déjà suffisamment généralisé.

$\begin{array}{lcc}\begin{array}{c}100 \text { arpents } \\ \text { et moins }\end{array} & \begin{array}{c}50 \text { arpents } \\ \text { et moins }\end{array} \\ \text { St-Clément } & 77 \% & 45 \% \\ \text { Ste-Martine } & 78 \% & 25 \% \\ \text { Georgetown } & 85 \% & 29 \% \\ \text { St-Timothée } & 85 \% & 57 \% \\ \text { St-Cyprien } & 92 \% & 57 \% \\ \text { St-Normand } & 91 \% & 65 \% \\ \text { St-Edouard } & 94 \% & 61 \%\end{array}$

Dans le district de Québec, à cet égard comme à bien d'autres, la situation paraît plus complexe. Là aussi le morcellement de la propriété foncière est une réalité tragique. La plupart des paroisses du comté de Kamouraska ressemblent à celles du district 
de Montréal. Mais des îlots de résistance se sont constitués avec le temps. Les concessions originelles de 60 ou de 90 arpents ont servi de noyaux pour la constitution de tenures plus vastes. Dans la paroisse de Lislet, $67 \%$ des propriétaires ont plus de 100 arpents de terre et $26 \%$ ont plus de 200 arpents. Le meilleur exemple est fourni par les cinq paroisses de la côte de Beaupré où $33 \%$ des propriétaires de terres possèdent plus de 200 arpents. Parmi eux, 60 propriétaires ont plus de 300 arpents de terre. Il est bien évident qu'à ces endroits le mouvement vers la concentration de la propriété foncière l'emporte sur le courant vers la fragmentation du sol. Il existe donc dans le district de Québec des groupes de paysans pour qui l'intégrité des patrimoines est une valeur transcendante. Par leur attitude, ces paysans ont sans doute contribué à perpétuer un certain type d'exploitation du sol assurant leur survie économique, mais ils ont aussi forcé plusieurs de leurs enfants à émigrer ou à entrer dans la masse des journaliers. En 1831 comme en 1842, la population du district de Québec est plus âgée que celle du district de Montréal. Il n'est pas exagéré de croire que de nombreuses paroisses du district de Québec étaient déjà, au XVIII ${ }^{e}$ siècle, des lieux d'émigration vers d'autres paroisses au sol plus riche et plus accessible ou encore vers le district de Montréal. Ces surplus de population dans la région de Québec auraient accru la pression démographique de la région de Montréal. Cette émigration interne, prélude de l'émigration aux Etats-Unis et des mouvements de colonisation, aurait d'abord débuté dans le district de Québec où aurait prévalu à bien des endroits le souci de préserver les patrimoines. Ici le pourcentage des non-propriétaires varie assez peu de 1831 à 1842: 27 et $28 \%$. Dans le district de Montréal, ces pourcentages sont de 29 et de $38 \%$.

Cette complexité du paysage humain en ce qui regarde la propriété foncière révèle d'autres complexités liées à la structure économique et sociale. Les campagnes du district de Québec offrent plus de diversité que celles de la région de Montréal où les contrastes paraissent beaucoup moins marqués. C'est cette complexité que nous voulons essayer de restituer.

\section{I. - La structure sociale}

En 1831, le district de Québec, dont la population est à peine plus de la moitié de celle du district de Montréal, compte 151935 habitants et $83 \%$ d'entre eux vivent à la campagne. Ce caractère rural de la population s'accentue, tout comme à Montréal, pendant la décennie: en 1842 , ce pourcentage est de $84 \%$ dans la région de Québec et de $90 \%$ dans celle de Montréal. 
Pendant cette décennie, la croissance démographique ralentit dans la ville de Québєc, sans doute affectée par la construction du canal Lachine: seulement $22 \%$ en 11 ans contre $26 \%$ de 1825 à 1831. La pression créée par la progression numérique des Anglophones en milieu urbain se relâche peu à peu durant la décennie. Ceux-ci qui constituent $44 \%$ des chefs de famille en 1831 ne sont plus que $40 \%$ en 1842 . Ils ne contribuent que de $19 \%$ à l'augmentation de la population. A Montréal, la supériorité numérique des Anglophones en milieu urbain au contraire s'accroît. Par contre, dans les campagnes du district de Québec la poussée démographique reste vigoureuse: $37 \%$ en onze ans contre $27 \%$ dans les milieux ruraux de la région de Montréal où a déjà commencé un mouvement de départs vers les Etats-Unis. Cette population se répartit entre moins de 90 localités dont 26 ont plus de 2000 habitants. Ste-Marie-de-Beauce et St-Gervais comptent plus de 4000 habitants. St-Louis de Lotbinière, Cap-Santé, La Malbaie, Pointe-Lévy, St-Henri de Lauzon, St-Thomas de Montmagny, St-Louis de Kamouraska, St-Rochdes-Aulnaies, St-Jean-Port-Joli et Rivière-Ouelle logent entre 2500 et 4000 personnes. A l'exception de la ville de Québec, la plupart des concentrations importantes se trouve sur la rive sud du fleuve.

La statistique sur laquelle repose cєtte analyse a été dégagée $\mathrm{du}$ recensement nominal de 1831. Elle englobe environ 70 paroisses, 18900 chefs de famille et une population de 120813 personnes. Il aurait été intéressant de pouvoir saisir le détail de leur évolution pendant toute la décennie. Mais le recensement nominal de 1842 renferme tellement de vides qu'il a fallu limiter notre enquête à une quinzaine de paroisses. Pour chaque chef de famille, nous n'avons retenu que sept variables: occupation, étendue de la terre, récolte: blé, avoine, pomme de terre, troupeaux: bêtes à cornes et porcs. A travers cette masse chiffrée, il est possible de se faire une idée, au moins élémentaire, de la structure sociale et de l'économie rurale.

\section{ÉCHELLE DES OCCUPATIONS: DISTRICT DE QUÉBEC}

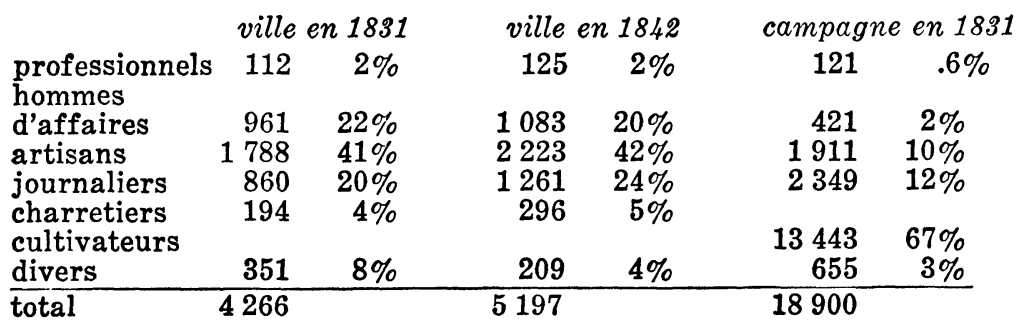


La société rurale est numériquement dominée par les cultivateurs, ceux qu'à certains endroits on nomme habitants ou agriculteurs. Le poids de la paysannerie n'est pas le même partout. Dans les paroisses où la colonisation est récente, les paysans constituent de 70 à $100 \%$ des chefs de famille. Certaines de ces localités sont situées très près de Québec: lac Beauport, Valcartier et le canton de Stoneham. Dans presque tous les townships du district de Québec, le cultivateur domine d'une façon écrasante la vie locale. Au lac Beauport et à Valcartier, les cultivateurs sont 95 et $82 \%$ des chefs de famille. Dans le comté de Rimouski, récemment ouvert à la colonisation sous l'effet de la pression démographique dans les paroisses moins éloignées, telle Rivière-du-Loup, le pourcentage des paysans dans onze jeunes localités est de $81 \%$. La même suprématie numérique de la paysannerie se retrouve dans des paroisses anciennes où l'accélération des concessions de terres, peut-être sous l'effet de l'immigration, semble s'être produite à la fin du XVIII ${ }^{\mathrm{e}}$ siècle. La Beauce appartient à cette catégorie. Dans quatre paroisses de cette région, les cultivateurs constituent de 81 à $89 \%$ des chefs de famille.

\begin{tabular}{lrrrrrrrr} 
& \multicolumn{1}{c}{$\begin{array}{l}\text { Rivière- } \\
\text { du-Loup }\end{array}$} & \multicolumn{2}{c}{ Rimouski } & \multicolumn{2}{c}{ Beauce } & \multicolumn{2}{c}{ Lotbinière } \\
professionnels & 1 & $.5 \%$ & 8 & $.6 \%$ & 12 & $.5 \%$ & 13 & $.9 \%$ \\
hommes & & & & & & & & \\
d'affaires & 12 & $7 \%$ & 13 & $.9 \%$ & 20 & $.9 \%$ & 11 & $.8 \%$ \\
artisans & 32 & $18 \%$ & 117 & $8 \%$ & 89 & $4 \%$ & 64 & $4 \%$ \\
journaliers & 34 & $20 \%$ & 87 & $6 \%$ & 149 & $7 \%$ & 98 & $7 \%$ \\
cultivateurs & 86 & $50 \%$ & 1083 & $81 \%$ & 1735 & $85 \%$ & 1111 & $83 \%$ \\
divers & 5 & $2 \%$ & 25 & $1 \%$ & 31 & $1 \%$ & 32 & $2 \%$ \\
\hline total & 170 & & 1333 & & 2036 & & 1329 &
\end{tabular}

Dans le comté de Rimouski, le sol n'est pas riche, mais le cultivateur peut aussi pratiquer la pêche et participer à la coupe du bois. La paroisse de Rivière-du-Loup, si le recensement est complet, ferait un peu figure de centre d'affaires de cette région. Par contre la Beauce et la région de Lotbinière paraissent plus exclusivement adonnées à l'agriculture. Mais, dans la Beauce, le morcellement de la propriété foncière est fortement engagé tandis que les jeunes de moins de 14 ans ne constituent que de 23 à $26 \%$ de la population. Cette région est un lieu d'émigration. Dans les cinq paroisses du comté de Lotbinière, l'emprise paysanne est aussi très forte, la population y est beaucoup plus jeune et la fragmentation du sol moins avancée. Le cas de l'Ile-auxCoudres est particulièrement intéressant de ce dernier point de vue. La place est ancienne et a, depuis longtemps, pris l'habitude 
de se délester de ses surplus de population qui gagnent la terre ferme: les moins de 14 ans ne sont que $19 \%$ de la population alors que ce pourcentage dépasse $40 \%$ dans le comté de Lotbinière. Les paysans en 1831 et en 1842 sont $92 \%$ des chefs de famille. Pendant cette décennie, même si l'équilibre des occupations est rigoureusement sauvegardé, le nombre des paysans augmente, mais au prix d'un certain morcellement de la terre: la proportion des propriétaires ayant plus de 100 arpents de terre passe de $52 \%$ à $31 \%$. Sur la terre ferme, excepté à La Malbaie où $46 \%$ de la population a moins de 14 ans, le vieillissement de la population est engagé. Là aussi la paysannerie est très nombreuse.

\begin{tabular}{lrc} 
& La Malbaie, Eboulements, Baie-St-Paul, \\
professionnels & \multicolumn{2}{c}{ Petite-Rivière, St-Joseph } \\
hommes d'affaires & 7 & $.5 \%$ \\
artisans & 28 & $2 \%$ \\
journaliers & 77 & $5 \%$ \\
cultivateurs & 133 & $10 \%$ \\
divers & 1037 & $80 \%$ \\
\hline total & 13 & $1 \%$ \\
\hline
\end{tabular}

Dans toutes ces paroisses, la paysannerie semble encore résister au mouvement vers le morcellement de la terre, ce qui entraîne forcément à quelques endroits le départ de jeunes. Il en est de même à l'île d'Orléans où $40 \%$ des exploitants possèdent entre 101 et 200 arpents de terre. Malgré le pourcentage impressionnant des non-propriétaires (42\% des chefs de famille), la paysannerie demeure très puissante: $75 \%$ des chefs de famille. Elle le serait davantage si l'île n'était le lieu de résidence de 34 pilotes, ce qui donne un relief accru au groupe artisanal. L'île d'Orléans, longtemps avant 1800, était un lieu d'émigration. Cette force numérique de la paysannerie se retrouve aussi dans les paroisses et seigneuries du comté de Portneuf, dont l'ancienneté ne fait pas de doute.

\begin{tabular}{lrrrr} 
& \multicolumn{2}{c}{ Ile d'Orléans } & Comté de Portneuf \\
professionnels & 3 & $.4 \%$ & 9 & $.4 \%$ \\
hommes d'affaires & 9 & $1 \%$ & 40 & $1 \%$ \\
artisans & 104 & $14 \%$ & 214 & $10 \%$ \\
journaliers & 29 & $4 \%$ & 138 & $6 \%$ \\
cultivateurs & 531 & $75 \%$ & 1581 & $76 \%$ \\
divers & 25 & $3 \%$ & 75 & $3 \%$ \\
\hline total & 701 & & 2057
\end{tabular}

La suprématie numérique de la paysannerie n'est pas la caractéristique exclusive des paroisses nouvellement colonisées. Elle a 
des rapports étroits avec la richesse du sol, la diversification de l'économie rurale et l'attachement à la propriété foncière.

Ces seigneuries et paroisses possèdent donc une physionomie fort différente de la plupart des localités rurales de la région de Montréal où les groupes artisanaux et les journaliers sont plus fortement représentés. Elles contrastent aussi avec un grand nombre de localités du district de Québec où la diversification des occupations est beaucoup plus avancée. Dans cinq paroisses de la seigneurie de Beaupré, le groupe paysan si richement doté de terres, ne constitue plus que $60 \%$ des chefs de famille. A cet endroit, la concentration des terres et, peut-être, l'exploitation forestière ont contribué à grossir le groupe des journaliers. L'émigration se fait par étapes.

\begin{tabular}{lrc} 
professionnels & 5 & $.9 \%$ \\
hommes d'affaires & 8 & $1 \%$ \\
artisans & 57 & $10 \%$ \\
journaliers & 113 & $21 \%$ \\
cultivateurs & 323 & $60 \%$ \\
divers & 24 & $4 \%$ \\
\hline total & 530 &
\end{tabular}

La proximité du marché urbain est sans doute un facteur aussi important de diversification des occupations que la pression démographique. Aux environs immédiats de Québec, les paroisses de Beauport, de Charlesbourg, de l'Ancienne-Lorette, de St-Ambroise, de Ste-Foy et de Cap-Rouge contiennent de nombreux "fermiers" et d'importantes concentrations de gens de métiers et de journaliers. Le nombre des cultivateurs n'atteint pas la moitié de celui des chefs de famille.

\begin{tabular}{lrc} 
professionnels & $\mathbf{1 1}$ & $\mathbf{. 9 \%}$ \\
hommes d'affaires & $\mathbf{4 7}$ & $\mathbf{3 \%}$ \\
artisans & 182 & $\mathbf{1 5 \%}$ \\
journaliers & 308 & $\mathbf{2 5 \%}$ \\
cultivateurs & 531 & $\mathbf{4 4 \%}$ \\
divers & 118 & $9 \%$ \\
\hline total & 1197 &
\end{tabular}

Il est certain que les facilités de contacts avec le marché urbain expliquent la présence de 65 "fermiers" pratiquant pour la plupart une agriculture de type commercial. Ainsi Thomas Bourke, fermier de Charlesbourg, récolte 5000 minots de pommes de terre et 700 minots d'avoine. De même l'existence de carrières de pierre à Beauport rend compte de la présence de 31 maçons dans cette localité. Ce ne sont là que des exemples montrant les rapports entre le nombre d'ouvriers spécialisés et les possibilités économiques de l'endroit. Il semble néanmoins que le groupe des 
journaliers soit beaucoup trop nombreux en regard des ressources de ces localités. Dans la paroisse St-Ambroise, lieu de fragmentation de la propriété foncière, les journaliers constituent $43 \%$ des chefs de famille. Ces localités sont certainement encombrées d'effectifs non spécialisés.

De l'autre côté du fleuve, face à la ville de Québec, les mêmes situations variées peuvent être observées. A Pointe-Lévy, St-Jean de Lauzon et à St-Nicolas les gens de métiers et les journaliers traduisent l'importance de l'exploitation forestière et des activités maritimes. Par contre à St-Henri de Lauzon et à St-Anselme, les cultivateurs conservent leur suprématie numérique. La structure des occupations dans ces deux groupes de paroisses montre ce contraste.

\begin{tabular}{lrcrc} 
& \multicolumn{2}{c}{ groupe I } & \multicolumn{2}{c}{ groupe II } \\
professionnels & 6 & $.5 \%$ & 3 & $.3 \%$ \\
hommes d'affaires & 63 & $5 \%$ & 11 & $1 \%$ \\
artisans & 167 & $15 \%$ & 40 & $4 \%$ \\
journaliers & 246 & $22 \%$ & 71 & $8 \%$ \\
cultivateurs & 602 & $54 \%$ & 706 & $82 \%$ \\
divers & 28 & $2 \%$ & 28 & $3 \%$ \\
\hline total & 1112 & & 859
\end{tabular}

Le long du fleuve vers l'aval, le comté de Bellechasse, formé de sept paroisses agricoles, en partie tournées vers les activités maritimes, possède une structure des occupations qui se rapproche de celle du district. Evidemment d'une paroisse à l'autre, les différences sont parfois très marquées: à St-Etienne-de-Beaumont, les cultivateurs ne sont que $40 \%$ des chefs de famille contre $80 \%$ à St-Charles. Partout cependant le vieillissement de la population est une tendance qui s'observe également dans les sept paroisses du comté de Lislet. Dans celles-ci les concentrations artisanales et les groupes de journaliers sont particulièrement impressionnants. Alors que dans les deux comtés précédents, les jeunes de moins de 14 ans constituent entre 19 et $24 \%$ de la population, ils représentent dans le comté de Kamouraska des pourcentages variant entre 42 et $50 \%$.

\begin{tabular}{lrcrrrr} 
& \multicolumn{3}{c}{ Bellechasse } & \multicolumn{2}{c}{ Lislet } & \multicolumn{2}{c}{ Kamouraska } \\
professionnels & 12 & $.6 \%$ & 18 & $.9 \%$ & 14 & $.6 \%$ \\
hommes d'affaires & 47 & $2 \%$ & 55 & $2 \%$ & 40 & $1 \%$ \\
artisans & 239 & $12 \%$ & 284 & $15 \%$ & 239 & $11 \%$ \\
journaliers & 222 & $11 \%$ & 412 & $21 \%$ & 287 & $13 \%$ \\
cultivateurs & 1363 & $70 \%$ & 1054 & $55 \%$ & 1364 & $65 \%$ \\
divers & 60 & $3 \%$ & 80 & $4 \%$ & 152 & $7 \%$ \\
\hline total & 1943 & & 1903 & & 2096 &
\end{tabular}

Comme le pourcentage des non-propriétaires est très élevé partout, particulièrement dans Lislet où il varie entre 29 et $43 \%$, 
et que les non-propriétaires sont généralement plus jeunes, l'âge moyen des exploitants agricoles doit être très élevé. Il est certain que dans Lislet les ouvriers non spécialisés, malgré l'ampleur de l'activité agricole, sont en trop grand nombre. Il n'est pas exagéré de croire que l'émigration est un phénomène bien établi dans la très grande majorité de ces paroisses et seigneuries.

L'intensité de la présence paysanne et, partant, la diversification des occupations sont donc liées à un ensemble de facteurs qui jouent à des degrés divers et différemment d'un endroit à l'autre. C'est pourquoi les variations sont tellement marquées: de 40 à $100 \%$ pour les cultivateurs. Les mêmes variations peuvent être observées à propos des gens de métiers dont l'existence dépend davantage de conditions économiques précises. Leur pourcentage varie entre zéro et $25 \%$. Dans l'ensemble cependant l'image du cultivateur qui fabrique lui-même ses souliers, construit sa maison, fait ses meubles, ferre ses chevaux, fabrique ses voitures et l'équipement de sa ferme appartient au passé. Peut-être $\epsilon n$ était-il ainsi dans la plupart des localités à l'époque de la Nouvelle-France, et probablement jusqu'aux dernières décennies du XVIII $I^{e}$ siècle, mais en 1830 cette époque est révolue dans la plupart des cas. Il est vrai que les endroits de colonisation récente font encore songer au passé: au lac Beauport, il y a 146 cultivateurs, un maçon, trois journaliers et trois instituteurs; à Valcartier, colonie surtout anglophone comme la précédente, on trouve 121 cultivateurs, un charron, 19 journaliers, quatre instituteurs et un missionnaire. Même les paroisses les plus mal pourvues à cet égard ont un nombre minimum de gens de métiers: un menuisier, un forgeron, un cordonnier et un meunier. Les paysans débrouillards, habiles à tout faire, se font de plus en plus rares, particulièrement dans les seigneuries bien développées. Les métiers les plus répandus sont les forgerons (378), les menuisiers (353), les charpentiers (111), les cordonniers (196), les charrons (106), les meuniers (94), les navigateurs (120) et les pilotes (92). Les effectifs par secteur sont les suivants:

métiers du bois et de la construction
métiers du fer
métiers du cuir
métiers de la mer
vêtement
meuniers
divers

Nombre d'artisans (10\% des chefs de famille)

total

\begin{tabular}{rr}
675 & $35 \%$ \\
520 & $27 \%$ \\
243 & $12 \%$ \\
316 & $16 \%$ \\
33 & $1 \%$ \\
94 & $4 \%$ \\
30 & $1 \%$ \\
\hline
\end{tabular}

1911 
Le développement des groupes d'artisans était d'abord une réponse aux besoins d'une population croissante dont l'existence dépendait surtout de l'agriculture. En 1831, celle-ci domine encore la vie locale. Depuis au moins 1760 , elle avait eu tendance à entrer dans le circuit commercial, ce qui avait favorisé une diversification des occupations. Ainsi le meunier est un personnage qui se retrouve dans presque toutes les seigneuries, sinon dans la plupart des paroisses. Il en est de même des forgerons, des menuisiers, des cordonniers et des charrons qui peu à peu ont pris place dans la société locale. Le secteur du vêtement est le plus faible. L'importation des toiles et des étoffes donne lieu à un commerce considérable tandis que la production de la laine et $d u$ lin, en expansion durant environ deux décennies, alimente aussi l'industrie domestique. Les tailleurs, les cardeurs, les couturières et les chapeliers sont encore peu nombreux dans les campagnes du district de Québec. Les femmes fabriquent les vêtements pour la famille. La croissance du commerce du bois a aussi stimulé à bien des endroits la multiplication des artisans et des métiers. Il faut dire en plus que l'exploitation forestière, particulièrement dans le district de Québec, procure de l'emploi à un grand nombre de cultivateurs, à leurs fils, et à bien des journaliers. Il en est de même des activités maritimes. La construction de chaloupes et de petits bateaux et la pêche confèrent une importance considérable aux métiers de la mer. En fait les ressources du district de Québec sont variées et la population y est finalement, malgré des sols souvent médiocres, moins tributaire d'une activité unique que dans la zone seigneuriale de Montréal. Cette diversité des activités autres que l'agriculture est un facteur de stabilité sociale. Il faut dire qu'elle ne s'exprime pas également en tous lieux.

Dans les régions où l'agriculture domine vraiment l'activité économique, la diversité des métiers et le nombre d'artisans restent le plus souvent limités. La Beauce, Lotbinière et la partie développée du comté de Saguenay appartiennent à cette catégorie: les artisans n'y sont que 4 ou $5 \%$ des chefs de famille. Si Ste-Marie-de-Beauce, avec sa population de 5113 qui allait tomber à 3075 habitants en dix ans, n'avait été un port intérieur, le nombre des gens de métiers aurait été encore plus réduit. Une agriculture plutôt mal en point et le modeste trafic, légal ou illégal, avec les Etats-Unis, ne pouvaient favoriser la multiplication des artisans. La situation dans Lotbinière et Saguenay est analogue. L'agriculture est l'activité dominante, mais la proximité du fleuve donne un certain relief à la pêche et, partant, à la construction de barques. 


cardeurs
charrons
forgerons
menuisiers
maçons
peintres
cordonniers
potiers
ferblantiers
selliers
couvreurs
meuniers
charpentiers
navigateurs
potassiers
tanneurs
voiliers
couturières
pilotes
chaloupiers
chaisiers
traversiers

Beauce
1
8
29
17
5
1
9
1
5
1
1
8
1
0
2
0
0
0
0
0
0
0

Lotbinière
0
5
21
18
2
0
7
1
0
0
0
3
4
2
0
1
0
0
0
0
0
0

$\begin{array}{cr}\text { Saguenay } & \text { Orléans } \\ 2 & 0 \\ 2 & 1 \\ 21 & 14 \\ 17 & 9 \\ 4 & 2 \\ 1 & 0 \\ 8 & 17 \\ 3 & 0 \\ 1 & 4 \\ 2 & 0 \\ 0 & 0 \\ 6 & 5 \\ 2 & 2 \\ 5 & 0 \\ 0 & 0 \\ 2 & 2 \\ 1 & 0 \\ 1 & 1 \\ 0 & 34 \\ 0 & 7 \\ 0 & 3 \\ 0 & 3\end{array}$

Dans les cinq paroisses agricoles de l'île d'Orléans où les artisans constituent $14 \%$ des chefs de famille, le pilotage, la construction de barques et de chaloupes sont des activités importantes.

La côte de Beaupré et la région de Portneuf présentent des contrastes plutôt saisissants même si les deux groupes de localités renferment le même pourcentage de gens de métiers $(10 \%)$.

forgerons
cordonniers
maçons
meuniers
menuisiers
navigateurs
cardeurs
tanneurs
charpentiers
ferblantiers
selliers
charrons
mineurs
couvreurs
tailleurs de clous
tailleurs
pilotes
peintres
mesureurs de bois
meubliers
tonneliers

forgerons

cordonniers

menuisiers

cardeurs

tanneurs

ferblantiers

selliers

mineurs

tailleurs

mesureurs de bois

tonneliers

Portneuf
43
16
19
17
32
40
3
2
10
0
1
12
0
1
2
1
2
2
1
4
6


La côte de Beaupré combine l'agriculture, l'exploitation de la forêt et l€s activités maritimes. La région de Portneuf, quatre fois plus populeuse, pratique l'agriculture, le cabotage, la pêche, la coupe du bois et possède un moulin à papier. La meunerie est aussi active. La diversité des ressources appelle la diversification des métiers. Aux environs de Québec et dans une partie du comté de Dorchester, face à la ville de Québec, la diversité est beaucoup plus poussée.

$\begin{array}{lcc} & \text { Environs de Québec } & \text { Dorchester } \\ \text { meuniers } & 6 & 7 \\ \text { menuisiers } & 35 & 37 \\ \text { forgerons } & 25 & 41 \\ \text { cordonniers } & 13 & 20 \\ \text { ferblantiers } & 1 & 5 \\ \text { charpentiers } & 13 & 11 \\ \text { charrons } & 27 & 4 \\ \text { maçons } & 45 & 3 \\ \text { cordiers } & 1 & 0 \\ \text { jardiniers } & 3 & 0 \\ \text { huiliers } & 1 & 0 \\ \text { tonneliers } & 1 & 1 \\ \text { couvreurs } & 1 & 0 \\ \text { scieurs } & 1 & 3 \\ \text { selliers } & 1 & 2 \\ \text { tailleurs } & 1 & 0 \\ \text { briqueleurs } & 1 & 0 \\ \text { mesureurs de bois } & 2 & 12 \\ \text { sculpteurs } & 1 & 0 \\ \text { horlogers } & 1 & 0 \\ \text { navigateurs } & 0 & 13 \\ \text { tanneurs } & 0 & 9 \\ \text { traversiers } & 0 & 23 \\ \text { calfats } & 0 & 2 \\ \text { pilotes } & 0 & 1 \\ \text { arrimeurs } & 0 & 3 \\ \text { pêcheurs } & 0 & 3 \\ \text { laveuses } & 0 & 1 \\ \text { chapeliers } & 0 & 1 \\ \text { chaloupiers } & 0 & 1 \\ \text { cardeurs } & 0 & 1 \\ \text { couturières } & 0 & 1 \\ \text { mineurs } & 0 & \end{array}$

Il est certain que la proximité de la ville stimule une agriculture de type commercial et la diversité des métiers. Par contre elle incite la population des localités très proches à recourir aux services de certains artisans urbains. Elle peut donc avoir des conséquences opposé $\epsilon$. Les concentrations de maçons dans les paroisses voisines de Québec et dans Portneuf s'expliquent autant par l'existence des carrières de pierre que par l'existence d'une 
clientèle à majorité urbaine. Plus de la moitié des maçons vivant dans les campagnes se trouve dans cette région restreinte. De même le nombre des charrons dans ces paroisses égale celui de la ville de Québec. Dans Dorchester, certaines paroisses ont une physionomie qui ressemble à celle de la Beauce où prime l'agriculture; d'autres logent une forte population d'artisans $(15 \%)$. Agriculture, commerce du bois, navigation, construction de navires y sont les principales activités économiques.

Entre Pointe-Lévy et Rivière-du-Loup, une vingtaine de paroisses agricoles au sol riche s'étalent le long du fleuve. L'agriculture, la pêche, le cabotage et la construction en petit de navires stimulent la multiplication des métiers et des artisans dont la proportion varie entre 11 et $15 \%$ des chefs de famille.

$\begin{array}{lcrc} & \text { Bellechasse } & \text { Lislet } & \text { Kamouraska } \\ \text { charrons } & 24 & 7 & 10 \\ \text { charpentiers } & 19 & 23 & 15 \\ \text { navigateurs } & 15 & 19 & 14 \\ \text { pilotes } & 17 & 2 & 3 \\ \text { forgerons } & 52 & 45 & 39 \\ \text { menuisiers } & 32 & 76 & 49 \\ \text { maçons } & 5 & 8 & 13 \\ \text { scieurs } & 2 & 0 & 1 \\ \text { meuniers } & 14 & 7 & 8 \\ \text { pêcheurs } & 12 & 43 & 1 \\ \text { tonneliers } & 2 & 8 & 8 \\ \text { cordonniers } & 17 & 24 & 41 \\ \text { selliers } & 1 & 2 & 2 \\ \text { mineurs } & 1 & 0 & 0 \\ \text { ferblantiers } & 8 & 1 & 6 \\ \text { tarneurs } & 9 & 4 & 4 \\ \text { cardeurs } & 3 & 2 & 1 \\ \text { couturières } & 2 & 0 & 1 \\ \text { poulieurs } & 1 & 0 & 0 \\ \text { couvreurs } & 2 & 1 & 5 \\ \text { tailleurs } & 1 & 1 & 2 \\ \text { mécaniciens } & 1 & 0 & 0 \\ \text { potiers } & 0 & 5 & 3 \\ \text { calfats } & 0 & 1 & 1 \\ \text { peintres } & 0 & 1 & 1 \\ \text { chapeliers } & 0 & 0 & 1 \\ \text { orfevres } & 0 & 1 & 0 \\ \text { horlogers } & 0 & 2 & 0 \\ \text { meubliers } & 0 & 1 & 1 \\ \text { femmes de ménage } & 0 & 0 & 0\end{array}$

Dans le comté de Rimouski, les artisans, inexistants dans plusieurs localités, sont en assez grand nombre dans certains centres plus populeux. Les métiers de la mer et ceux du bois l'emportent. L'agriculture peu rémunératrice favorise mal la diversité des occupations. 


$\begin{array}{lr}\text { forgerons } & 26 \\ \text { charpentiers } & 6 \\ \text { pilotes } & 34 \\ \text { meuniers } & 9 \\ \text { cordonniers } & 10 \\ \text { navigateurs } & 9 \\ \text { menuisiers } & 35 \\ \text { maçons } & 2 \\ \text { charrons } & 2 \\ \text { ferblantiers } & 1 \\ \text { tailleurs } & 1 \\ \text { potiers } & 2 \\ \text { tonneliers } & 2 \\ \text { mesureurs de bois } & 1 \\ \text { arrimeurs } & 1 \\ \text { armuriers } & 1\end{array}$

La présence paysanne et celle des gens de métiers expriment donc un équilibre entre trois activités économiques principales: l'agriculture qui d'une façon ou d'une autre a acquis un caractère commercial, l'exploitation de la forêt pour répondre aux besoins locaux ou aux nécessités du commerce international, et la pêche. Le cabotage et la navigation océanique ont par conséquent leur effet sur la structure des occupations. Le recensement ne nous permet pas de dire s'il y avait surplus ou pénurie de gens de métiers. Il est bien possible que, dans plusieurs localités, les menuisiers et les forgerons se soient multipliés trop vite. Les conditions économiques de la décennie 1831-42, si on en juge par les paroisses de Deschambault et de Cap-Santé, semblent avoir imposé un frein à la croissance des gens de métiers. Dans ces deux paroisses, le nombre des artisans passe de $73(17 \%)$ en 1831 à $66(11 \%)$ en 1842 . Le nombre des navigateurs régresse de 25 à 19 , celui des forgerons de 9 à 8 et celui des menuisiers de 10 à 6 . Par contre les paysans s'accroissent proportionnellement plus vite: 66 à $79 \%$ des chefs de famille. Mais ces gains se font au prix d'un morcellement de la propriété foncière: le pourcentage de ceux qui possèdent 100 arpents de terre et moins est de $64 \%$ en 1842 contre $54 \%$ en 1831. Tout cela accompagne la détérioration de l'agriculture: en 1831, $48 \%$ des producteurs de blé récoltent 50 minots et moins; en 1842 , tous les cultivateurs produisent 50 minots et moins. Le nombre des producteurs de blé est passé de 279 à 41 . Les troupeaux eux-mêmes ont décliné. Quant aux journaliers, ils sont proportionnellement moins nombreux: de 7 à $5 \%$ des chefs de famille. 
La croissance des effectifs des travailleurs non spécialisés est un problème plus complexe. Disons d'abord que le groupe souffre au point de départ de la compétition des cultivateurs et des fils d'habitants qui depuis longtemps ont pris l'habitude de chercher un supplément de revenu hors de la ferme, que ce soit dans le commerce des fourrures, l'exploitation forestière, la construction navale et la pêche. En second lieu, la constitution d'une classe de journaliers dépend directement de la croissance démographique et de l'attitude des paysans à l'égard de la propriété foncière. Enfin le groupe fluctue en regard des conditions économiques. Prenons le cas de l'île d'Orléans où les journaliers ne sont que $4 \%$ des chefs de famille. En 1765, cette île avait une population de 2285 habitants. Nous savons par ailleurs que la population canadienne-française avait tendance à doubler ses effectifs tous les vingt-cinq ans. Ceci veut dire qu'en 1790 le nombre d'habitants sur l'île aurait pu être environ de 4500 . En fait ce n'est qu'en 1831 qu'il approche ce chiffre avec 4349 personnes. Il est évident que l'île a connu une émigration au $\mathrm{XVIII}^{\mathrm{e}}$ siècle. Le morcellement excessif des terres ne s'est pas produit, pas plus que la constitution d'un énorme groupe de journaliers. La jeunesse ou des familles complètes ont appris à gagner la terre ferme. Sur la côte de Beaupré, le phénomène de base est le même: la croissance de la population est très lente et la fragmentation de la propriété est évitée, mais là se bâtit un important groupe de journaliers : $21 \%$ des chefs de famille. Ce prolétariat, même s'il comprend un certain nombre de travailleurs agricoles et forestiers, est aussi formé de candidats à l'émigration ou à la propriété foncière si fortement concentrée dans ces paroisses.

\section{LES JOURNALIERS PAR GROUPES DE PAROISSES}

$\begin{array}{lrr}\text { Rimouski } & 121 & 8 \% \\ \text { Beauce } & 149 & 7 \% \\ \text { Lotbinière } & 98 & 7 \% \\ \text { Saguenay } & 133 & 10 \% \\ \text { lle d'Orléans } & 29 & 4 \% \\ \text { Beaupré } & 113 & 21 \% \\ \text { Environs de Québec } & 308 & 25 \% \\ \text { Dorchester I } & 246 & 22 \% \\ \text { Dorchester II } & 71 & 8 \% \\ \text { Bellechasse } & 222 & 11 \% \\ \text { Lislet } & 412 & 21 \% \\ \text { Kamouraska } & 287 & 13 \%\end{array}$

Dans les groupes de paroisses à vocation agricole fortement prédominante, la main-d'œuvre non spécialisée comprend de 4 à $10 \%$ des chefs de famille. Il s'agit en fait d'un minimum puisque 
le recensement ne mentionne pas l'identité et l'occupation de ceux qui ne sont pas membres de la famille et qui habitent avec elle. Cela est particulièrement important dans les endroits où l'activité économique est davantage diversifiée et intense. Ainsi, dans les paroisses où l'agriculture domine vraiment et où la qualité du sol laisse souvent à désirer, le phénomène de l'émigration se dessine plus rapidement ce qui empêche le grossissement du groupe des journaliers. La même situation existe dans bien des localités où les détenteurs de la propriété ont tendance à refuser le morcellement. Autour de la ville de Québec, les journaliers sont en grand nombre: $18 \%$ à Charlesbourg, $22 \%$ à l'Ancienne-Lorette et $43 \%$ à St-Ambroise. Ils ne sont certainement pas là avec l'espoir d'obtenir des terres: l'occupation du sol est très avancée de même que le morcellement de la propriété foncière. Ils espèrent sans doute trouver de l'emploi d'une façon saisonnière ou permanente dans la ville de Québec où, au début de cette décennie, les perspectives ne sont pas éclatantes. Peutêtre pouvaient-ils s'employer comme ouvriers agricoles durant l'été et comme manœuvres dans la construction navale durant l'hiver. De l'autre côté du fleuve, la situation semble meilleure. L'exploitation for $€$ stière dans une partie du comté de Dorchester fournit de l'emploi à de nombreux journaliers. Dans les paroisses agricoles plus riches, le long du fleuve, les ouvriers non spécialisés sont aussi en grand nombre. Leur accumulation avait certainement un rapport direct avec le refus des détenteurs de terres d'accepter le morcellement de leurs propriétés. Encore là une distinction s'impose. Même lorsqu'ils refusent la subdivision des terres en faveur de leurs enfants, les propriétaires consentent à détacher de petites parcelles de leurs biens pour fins de location. Ainsi, à St-Roch-des-Aulnaies et à Lislet, 37 et $43 \%$ des chefs de famille sont non-propriétaires. C'est dans le comté de Bellechasse, dans celui de Lislet et de Kamouraska, que les locataires sont les plus nombreux. D'ailleurs ceux-ci se recrutent surtout parmi les journaliers. A St-Roch-des-Aulnaies, Lislet, St-JeanPort-Joli et à Rivière-Ouelle, le pourcentage des journaliers varie entre 21 et $26 \%$. En réalité, l'émigration est une vieille histoire dans le district de Québec. Très peu de paroisses ont été capables à partir de 1760 d'absorber toute la croissance naturelle de leur population. Les départs des jeunes et des moins jeunes pouvaient dans certains cas être immédiats ou, dans d'autres, se faire après un stage parmi les ouvriers non spécialisés. Un dernier exemple illustre c€t écart entre la croissance économique et la croissance démographique. La paroisse de Deschambault a une population de 695 habitants en 1784. De 1794 à 1821, la croissance naturelle est de 896 personnes. En 1831, la population n'est encore 
que de 1384 habitants. Cette localité semble à cet égard représentative de tout le district. La présence plus ou moins grande de journaliers dans une localité donnée ne provient pas d'un facteur unique.

Malgré la dévaluation de la propriété foncière durant ces années, la possession de la terre est toujours un élément qui sert à définir le statut social. Dans cette perspective, le journalier se situe au bas de l'échelle sociale. L'instabilité qui entoure son existence, ses difficultés d'accès à la propriété foncière tout comme ses aspirations en cette direction, et le caractère trop souvent précaire des conditions économiques qui justifieraient dans la plupart des cas des groupes moins nombreux, en font un individu dévalorisé. Dans 70 paroisses recensées, seulement deux journaliers possèdent plus de 300 arpents de terre. Viennent ensuite les gens de métiers dont l'utilité sociale est reconnue et qui se trouvent en plus grand nombre parmi les propriétaires. Une dizaine d'entre eux est parmi ceux qui possèdent entre 300 et 400 arpents de terre. Tout cela évidemment n'empêche pas le journalier et l'artisan du village, lorsqu'ils sont bien établis, de manifester une certaine hauteur à l'endroit du paysan; mais la société bas-canadienne valorise davantage, du moins elle le prétend, le cultivateur propriétaire. Celui-ci paraît plus à l'abri des circonstances défavorables. Ces vues rassurantes, justifiables si on songe que la paysannerie contrôle en grande partie la propriété foncière et qu'elle fournit la majorité des gros propriétaires de terres, paraissent plus contestables lorsqu'il est tenu compte de la pression démographique, du morcellement de la propriété foncière et des bouleversements que subit l'agriculture. Le monde paysan vit aussi dans l'incertitude et le poids de ses éléments défavorisés augmente rapidement. Partout cependant des minorités paysannes semblent en mesure de figurer parmi les élites locales.

Les élites locales, celles qui détiennent le plus d'influence et de pouvoir, viennent de groupes plus restreints: seigneurs, prêtres et marchands. Le recensement qui n'identifie que 30 seigneurs ne permet pas de se former une idée exacte de ce groupe. Disons que tout le territoire anciennement concédé était divisé en seigneuries. De nombreux arrière-fiefs avaient été taillés à même ces seigneuries. Enfin les pratiques successorales et les mauvaises affaires avaient provoqué de nombreuses subdivisions. Ce groupe seigneurial, qui réside ou qui administre par des agents, comprend une centaine de personnes. Les institutions 
religieuses possèdent une proportion appréciable des seigneuries rurales et urbaines. Ainsi le Séminaire de Québec est seigneur de toute la côte de Beaupré. Les Ursulines possèdent des fiefs dans les campagnes. L'Etat contrôle directement les anciennes seigneuries des Jésuites, en particulier St-Gabriel, Notre-Damedes-Anges et la seigneurie de Lauzon. Les autres seigneuries sont la propriété de particuliers. Des descendants des anciennes familles aux prétentions nobiliaires font partie de ce groupe: les Taschereau, les De Lotbinière, les De Salaberry et les Duchesnay sont les plus voyants. Des marchands et des professionnels sont aussi entrés dans ce groupe restreint. En 1831, la seigneurie est une institution encore bien vivante. Par leurs revenus et par leur position, les seigneurs exercent dans beaucoup de localités une influence déterminante sur la vie locale. Le recensement, s'il ne permet pas d'établir les quantités de terres non concédées, indique néanmoins les surfaces concédées sujettes aux droits seigneuriaux et l'étendue des domaines qui varie entre 250 et 1300 arpents. En 1831, les revenus des seigneuries du Séminaire de Québec sont de 159218 livres courantes françaises. A cette date, le morcellement des fiefs contrôlés par les laïques est tel qu'il est très difficile, en l'absence de monographies, de généraliser à propos du revenu des seigneurs et coseigneurs. Le cadastre abrégé de 1854 , qui mentionne les noms de ces derniers pour chaque seigneurie, est extrêmement révélateur à cet égard: quinze noms pour Rivière-du-Sud, douze pour Lespinay, seize pour l'île Verte et vingt-six pour Trois-Pistoles. A bien des endroits, il s'agit d'une véritable désintégration de la propriété seigneuriale. Ainsi le prestige, le revenu et le pouvoir des seigneurs varient d'une façon extraordinaire sur l'étendue du territoire. Les différences de niveau entre les seigneurs sont énormes.

Le pouvoir se trouve aussi dans les mains des curés. La pénurie de prêtres se fait encore sentir: 56 localités ont leur curé; mais ce n'est qu'un phénomène temporaire. Deux séminaires, l'un à Québec et l'autre à Ste-Anne-de-la-Pocatière, ont comme but principal le recrutement sacerdotal. Même s'il n'y a que très peu de curés parmi les gros propriétaires fonciers - celui de Baie-St-Paul possède 640 arpents et celui de l'île Verte en déclare 672 - , le revenu de la plupart des curés égale au moins celui des plus riches fermiers. Ce revenu comme celui des paroisses fluctue en fonction de la conjoncture économique et de la générosité des fidèles. Mais le prestige des curés ne dépend pas uniquement de leur statut économique. Il est surtout lié à un ensemble de rapports religieux et autres que les clercs entretiennent avec les communautés rurales. La paroisse est l'institution sur 
laquelle s'appuie le pouvoir clérical. Les marguilliers, les bedeaux et les instituteurs - ceux-ci au nombre de 198 -, malgré les querelles qui entourent la gestion des fabriques et le contrôle des écoles, servent à la fois l'autorité des curés et les objectifs multiples de l'institution religieuse. Le pouvoir des curés fait l'objet de contestation, mais le temps semble jouer en faveur du pouvoir clérical.

Les professionnels font aussi partie des élites rurales. Dans les 70 localités analysées, ils sont au nombre de 121:65 notaires, 7 avocats, 30 médecins, 17 arpenteurs, 1 ingénieur et 1 architecte. Il faudrait peut-être ajouter à ce groupe 30 huissiers. Encore là il s'agit d'un groupe en expansion dont les collèges classiques assurent le recrutement premier. Il est certain que les professionnels ne doivent pas leur influence à l'ampleur de leur propriété foncière. A cet égard, ils sont mieux situés que les instituteurs - un seul parmi ces derniers est grand propriétaire: J.-M. Michaud de Rivière-du-Loup possède 2040 arpents de terre -; mais leur situation est loin d'être brillante: un médecin, deux notaires et trois arpenteurs ont des propriétés dont l'étendue varie entre 300 et 1200 arpents. Ce sont vraiment des exceptions. Deux huissiers figurent aussi parmi les propriétaires importants. Pourtant ces professionnels, notaires, arpenteurs et huissiers, étaient mêlés aux transactions de la propriété foncière. Il serait dangereux de représenter les hommes de profession ruraux comme les serviteurs aveugles d'un système social défini et voulu par les seigneurs ou les curés. Dans les campagnes, le pouvoir est à cette époque une réalité mouvante et fait l'objet d'une contestation dont les professionnels sont les principaux artisans. Les avocats ne sont pas vraiment importants: sur sept avocats, cinq habitent des localités situées très près de la ville de Québec; un autre pratique à Ste-Marie-de-Beauce et le septième à Rivière-Ouelle. Les notaires et les médecins sont les plus actifs du groupe. Ils sont les vrais définisseurs de situation.

La bourgeoisie d'affaires est numériquement plus importante que les autres groupes. Elle comprend 421 individus dont 228 marchands et négociants, 148 aubergistes, 13 boulangers, 9 bouchers et 11 commis. Si on ajoute à ces éléments 36 personnes se définissant comme bourgeois et 52 comme rentiers, les effectifs d'affaires atteignent 509, soit $2.6 \%$ des chefs de famille. Ces commerçants locaux, qui assurent le ravitaillement des campagnes selon les besoins du marché, font des expéditions de pro- 
duits vers Québec, sont mêlés assez souvent à l'exploitation forestière, aux pêcheries et au transport par eau, sont en même temps des pourvoyeurs de crédit dans les campagnes. Fait assez surprenant, ils ne sont pas les principaux agents de la concentration des terres: seulement 24 individus sur les 509 mentionnés possèdent entre 300 et 3000 arpents. Parmi eux, ceux qui ont plus de 1000 arpents de terre sont rares: J. Moreau, marchand de Beaumont, possède 1200 arpents de terre, J.-M. Bélanger de StThomas 1671, L. Bertrand de l'île Verte en a 1932, H. Davis, marchand de Baie-St-Paul contrôle 3000 arpents de terre et John Graves, bourgeois, en déclare aussi 3000 dans le comté de Portneuf. Cette bourgeoisie d'affaires participe aussi au pouvoir ou à la lutte pour l'obtenir.

Même si les Canadiens français sont l'immense majorité de la population, la présence anglophone n'en est pas moins appréciable dans les campagnes. D'abord les townships dont la population est de 3500 sont peuplés en grande majorité par des Anglophones. Ainsi, dans le canton de Leeds, on ne dénombre que quelques journaliers canadiens-français sur 108 chefs de famille. Cette localité a 3 marchands, 2 aubergistes, un meunier, un charpentier et 91 cultivateurs. Il existe aussi des endroits à l'intérieur du territoire seigneurial où des majorités anglophones sont établies. A Valcartier, au lac Beauport et, à un moindre degré, dans la paroisse St-Sylvestre, les Anglophones forment presque la masse des cultivateurs. Dans cette dernière circonscription, ils sont 160 sur 236. Dans le comté de Portneuf, de fortes concentrations anglophones habitent certaines paroisses. Dans le comté de Rimouski, ils sont majoritaires en quelques endroits. Partout ailleurs, ils vivent isolés dans les anciennes paroisses ou constituent de faibles minorités. Au total la population anglophone ne dépasse pas 7 ou $8 \%$ de la population rurale du district. Ce n'est donc pas sur le plan numérique que la présence des Anglophones prend sa signification. Non seulement elle établit la diversité ethnique, parfois religieuse, dans les localités rurales, mais elle prolonge les disparités déjà observées dans les villes et les localités rurales de la région de Montréal entre les groupes ethniques. Le tableau suivant illustre cet aspect de la question.

POURCENTAGE DES ANGLOPHONES

DANS CERTAINES OCCUPATIONS

$\begin{array}{cccc} & \text { Nombre } & \% & \text { total } \\ \text { professionnels } & 21 & 17 \% & 121 \\ \text { notaires } & 5 & 7 \% & 65 \\ \text { médecins } & 11 & 36 \% & 30\end{array}$




$\begin{array}{lrrr}\text { avocats } & 3 & 42 \% & 7 \\ \text { arpenteurs } & 2 & 11 \% & 17 \\ \text { hommes d'affaires } & 90 & 21 \% & 421 \\ \text { marchands } & 45 & 19 \% & 228 \\ \text { aubergistes } & 25 & 16 \% & 148 \\ \text { commis } & 10 & 90 \% & 11 \\ \text { artisans } & 160 & 8 \% & 1911 \\ \text { menuisiers } & 17 & 4 \% & 353 \\ \text { meuniers } & 19 & 20 \% & 94 \\ \text { forgerons } & 13 & 3 \% & 378 \\ \text { cordonniers } & 35 & 17 \% & 196 \\ \text { charpentiers } & 15 & 13 \% & 111 \\ \text { navigateurs } & 6 & 5 \% & 120 \\ \text { macons } & 1 & 52 \% & 112 \\ \text { tailleurs } & 3 & 23 \% & 7 \\ \text { selliers } & 3 & 7 \% & 13 \\ \text { tonneliers } & 2 & 43 \% & 28 \\ \text { mesureurs de bois } & 7 & & 16 \\ \text { divers } & & 23 \% & 199 \\ \text { fermiers } & 47 & 33 \% & 30 \\ \text { seigneurs } & 10 & 41 \% & 36 \\ \text { bourgeois } & 15 & 16 \% & 198 \\ \text { instituteurs } & 33 & & \end{array}$

L'ethnicité est donc un facteur qui complique l'analyse de la structure sociale et du pouvoir sous toutes ses formes. Si le Canadien français établi dans les cantons fait le plus souvent figure de défavorisé, il n'en est pas ainsi pour les Anglophones dans la majorité des cas. Ceux-ci se situent de façon avantageuse dans l'échelle des occupations. Un tiers des seigneurs mentionnés comme tels au recensement est d'origine britannique. Ce sont d'ailleurs les seigneurs les plus engagés dans les différentes formes d'activités économiques. Leur influence ne vient pas uniquement des valeurs plus ou moins résistantes attachées à la propriété seigneuriale; elle résulte aussi de leur rôle économique. Dans la région du golfe, dans Portneuf, à La Malbaie et à Lauzon, les seigneurs anglophones ont une activité diversifiée. Parmi les professionnels, dont ils composent $17 \%$ des effectifs, la présence anglophone se fait sentir d'une façon inégale. Si elle paraît faible au sein du notariat, profession canadienne-française par excellence, elle s'affirme bien davantage parmi les médecins. Chez les arpenteurs, elle dépasse de manière appréciable le taux de $7 \%$ qui est celui des Anglophones dans l'ensemble de la population.

C'est parmi les milieux d'affaires que la représentation anglophone est la plus forte: $21 \%$ des effectifs totaux. Les Anglophones sont en grand nombre dans le groupe le plus répandu: celui des marchands et des aubergistes. Les commis qui sont 
peut-être des apprentis marchands, sont presque tous d'origine britannique. Le brasseur, les distilleurs, le fabricant de papier et le fabricant d'huile appartiennent tous à ce groupe ethnique. Les bourgeois, même si la plupart d'entre eux habitent dans le voisinage de la ville, sont à $41 \%$ anglophones. Dans les métiers, il n'est pas possible de parler de sur-représentation: $8 \%$ des gens de métiers sont d'origine britannique. Dans certains métiers cependant, les Anglophones détiennent une position forte: 4\% parmi les menuisiers, mais $13 \%$ chez les charpentiers, $3 \%$ des forgerons, mais $17 \%$ des cordonniers, $5 \%$ des navigateurs, mais $20 \%$ des meuniers. Ils fournissent aussi une forte proportion des effectifs chez les mesureurs de bois (les colleurs) : $43 \%$.

Il est évident que les Anglophones sont mieux représentés dans les occupations qui procurent les meilleurs revenus, davantage de prestige et de pouvoir, et qui exigent un plus haut niveau d'instruction. Les curés, les notaires, les menuisiers, les forgerons, les cultivateurs et les journaliers restent les occupations favorites des Canadiens français. Les fermiers, qui représentent souvent l'élite de la classe agricole, sont dans une proportion de $23 \%$ anglophones. Le nombre d'instituteurs qui n'est pas une garantie d'alphabétisme, est plus élevé parmi ceux-ci que chez les Canadiens français: $16 \%$ d'entre eux sont d'origine britannique. Les premiers, même les Irlandais, valorisent davantage l'instruction. Dans les paroisses St-Gilles et St-Sylvestre, comté de Lotbinière, 115 familles sur un total de 314 sont canadiennes-françaises, mais les quatre instituteurs sont anglophones. Dans la seigneurie de Beauport, habitée par 446 familles dont 275 canadiennes-françaises, le recensement indique la présence de deux instituteurs canadiens-français sur six. De même la population de Portneuf semble proportionnellement mieux desservie à cet égard chez les Anglophones que chez les Francophones. Six enseignants sur vingt sont de langue anglaise. Dans la mesure où le nombre d'instituteurs constitue un indicateur valable du niveau d'instruction, il aide à mettre en lumière certaines disparités ayant joué un rôle important dans la mise en place des disparités socioéconomiques entre les groupes ethniques.

Ces disparités ne s'expriment pas de la même façon sur tous les points du territoire seigneurial. Certaines paroisses peu éloignées de la ville de Québec n'ont que peu d'Anglophones. Charlesbourg n'en abrite que huit: un marchand, six cultivateurs et un fermier. L'Ancienne-Lorette avec six Anglophones dont un cultivateur, et St-Ambroise avec deux, un marchand et un bourgeois, présentaient peu d'attraits pour les Britanniques. Par contre à Beauport, Petite-Rivière St-Charles, Ste-Foy et Cap- 
Rouge, la présence anglophone est intense et même écrasante si on regarde plus loin que les chiffres relatifs aux occupations.

\begin{tabular}{lrrrrr} 
& \multicolumn{1}{c}{ Francophones } & \multicolumn{3}{c}{ Anglophones } & total \\
professionnels & 4 & $1 \%$ & 6 & $4 \%$ & 10 \\
hommes d'affaires & 14 & $3 \%$ & 26 & $18 \%$ & 40 \\
artisans & 74 & $18 \%$ & 21 & $14 \%$ & 95 \\
cultivateurs & 164 & $42 \%$ & 18 & $12 \%$ & 182 \\
journaliers & 96 & $24 \%$ & 12 & $8 \%$ & 108 \\
divers & 38 & $9 \%$ & 59 & $41 \%$ & 97 \\
\hline total & 390 & \multicolumn{4}{c}{142}
\end{tabular}

Ces localités subissent profondément l'influence de la ville. Les professionnels qui les habitent, en particulier les avocats, ont besoin de ce milieu. Mais ces endroits sont éminemment favorables à une agriculture de type commercial. En ce domaine le cultivateur propriétaire ne règne pas en maître: c'est le fermier, locataire de terre, qui en est la vedette. A ce niveau, les pourcentages n'ont plus de sens, car le dynamisme individuel seul compte. Sur 64 fermiers, 31 sont canadiens-français. Mais les disparités au niveau de la production sont au moins aussi énormes que dans la paroisse de Montréal.

De l'autre côté du fleuve, Pointe-Lévy, un centre plutôt actif, attire les habitants d'origine britannique. Entre autres, on y dénombre sept hommes d'affaires, onze artisans, un ministre du culte, deux instituteurs, un capitaine, un juge de paix et un seigneur. Dans le voisinage, un certain nombre d'Anglophones, probablement à cause de l'activité forestière, exercent leur métier. A St-Jean de Lauzon et à St-Nicolas, l'équilibre des groupes ethniques dans les différentes occupations est le suivant.

\begin{tabular}{|c|c|c|c|c|c|}
\hline \multirow{4}{*}{$\begin{array}{l}\text { professionnels } \\
\text { hommes d'affaires }\end{array}$} & \multicolumn{2}{|c|}{ Francophones } & \multicolumn{2}{|c|}{ Anglophones } & total \\
\hline & 3 & $\ldots$ & 0 & - & 3 \\
\hline & 12 & $2 \%$ & 14 & $21 \%$ & 26 \\
\hline & 38 & $8 \%$ & 15 & $22 \%$ & 53 \\
\hline cultivateurs & 248 & $54 \%$ & 11 & $16 \%$ & 259 \\
\hline journaliers & 144 & $31 \%$ & 25 & $37 \%$ & 169 \\
\hline divers & 12 & $2 \%$ & 1 & $1 \%$ & 13 \\
\hline total & 457 & & 66 & & 523 \\
\hline
\end{tabular}

Dans le comté de Lotbinière, deux paroisses de colonisation plus récente, St-Gilles et St-Sylvestre, sont habitées par une majorité d'Anglophones. Ces paroisses n'ont pas de curés, mais elles ont un notaire, trois aubergistes, quatre instituteurs et trois fermiers. La très grande majorité des chefs de famille est formée de cultivateurs. 


\begin{tabular}{|c|c|c|c|c|c|}
\hline & \multicolumn{2}{|c|}{ Francophones } & \multicolumn{2}{|c|}{ Anglophones } & total \\
\hline 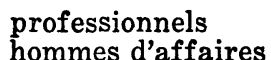 & $\begin{array}{l}1 \\
1\end{array}$ & 二 & $\begin{array}{l}0 \\
2\end{array}$ & $\overline{1 \%}$ & $\begin{array}{l}1 \\
3\end{array}$ \\
\hline artisans & $\overline{1}$ & - & $\overline{1}$ & & \\
\hline cultivateurs & 113 & $96 \%$ & 182 & $91 \%$ & 29 \\
\hline journaliers & 1 & - & 6 & $3 \%$ & \\
\hline divers & 0 & 二 & 7 & $3 \%$ & \\
\hline total & 117 & & 198 & & 31 \\
\hline
\end{tabular}

Un dernier exemple illustrera ce phénomène des rapports entre les groupes ethniques au plan des occupations. Il s'agit de la paroisse de Rivière-du-Loup, un autre centre régional assez actif.

\begin{tabular}{|c|c|c|c|c|c|}
\hline \multirow{6}{*}{$\begin{array}{l}\text { professionnels } \\
\text { hommes d'affaires } \\
\text { artisans } \\
\text { cultivateurs } \\
\text { journaliers }\end{array}$} & \multicolumn{2}{|c|}{ Francophones } & \multicolumn{2}{|c|}{ Anglophones } & total \\
\hline & 1 & - & 0 & - & 1 \\
\hline & 6 & $4 \%$ & 6 & $23 \%$ & 12 \\
\hline & 21 & $14 \%$ & 11 & $42 \%$ & 32 \\
\hline & 81 & $56 \%$ & 5 & $19 \%$ & 86 \\
\hline & 31 & $21 \%$ & 3 & $11 \%$ & 34 \\
\hline divers & 3 & $2 \%$ & 1 & $3 \%$ & 4 \\
\hline total & 143 & & 26 & & $\overline{169}$ \\
\hline
\end{tabular}

Dans la plupart des anciennes paroisses, la présence des Anglophones se traduit par l'action de quelques individus qui n'exercent pas toujours une influence à l'intérieur de la communauté. A St-Anselme de Lauzon, le meunier, le menuisier, trois cultivateurs et deux journaliers sont d'origine britannique. Le nombre de chefs de famille y est de 306. A Beaumont, le seigneur, un marchand sur sept, quatre artisans sur trente-sept sont anglophones. A l'île Verte, les membres de la famille Fraser, qui ne sont pas les seuls Britanniques de l'endroit, possèdent plus de 3000 arpents de terre. En général, dans le comté de Rimouski, les Anglophones sont nombreux et bien situés dans la structure des occupations. Par contre ils sont presque totalement absents de plusieurs paroisses de la rive nord: les Eboulements et l'Ileaux-Coudres. Dans les cinq paroisses de la côte de Beaupré, un menuisier n'est pas canadien-français. A l'île d'Orléans, un médecin et deux ferblantiers composent la population britannique. Tout cela montre le caractère inégal de cette présence dans les milieux ruraux du district de Québ€c où très souvent elle suffit à suggérer des questions à propos de l'inégalité des destins.

\section{II. - La répartition et l'exploitation du sol}

La répartition de la terre offre aussi ses complexités. Il n'est donc pas possible, malgré l'existence de certains traits com- 
muns, de présenter le phénomène en fonction d'un concept unique. Même les paroisses de colonisation récente présentent des différences appréciables. Il est certain que les Anglophones se faisaient une image différente de la propriété fonciere. Pour eux, une concession de terre normale devait avoir entre 150 et 200 arpents tandis que, pour le Canadien français, l'idéal pouvait se situer autour de 90 ou 100 arpents. A cet égard, la situation qui prévaut dans le township de Leeds semble assez représentative: $60 \%$ des cultivateurs ont plus de 100 arpents de terre. Dans l'aire seigneuriale où la tradition est différente et où les circonstances le sont devenues, les concessions originelles ont tendance à être plus réduites. Ainsi, dans le comté de Rimouski, le facteur ethnique, tant chez les seigneurs que chez les censitaires, semble avoir eu une influence considérable sur l'étendue des octrois de terre. A Mîtis, par exemple, le seigneur et presque toute la population sont d'origine britannique.

\begin{tabular}{|c|c|c|c|c|c|c|}
\hline arpents & & $e d s$ & Rim & $u s k i$ & & itis \\
\hline $0-50$ & 1 & $1 \%$ & 82 & $7 \%$ & 0 & - \\
\hline $51-100$ & 35 & $37 \%$ & 541 & $46 \%$ & 2 & $8 \%$ \\
\hline $101-200$ & 33 & $35 \%$ & 354 & $30 \%$ & 13 & $52 \%$ \\
\hline 201 et plus & 24 & $25 \%$ & 185 & $15 \%$ & 10 & $40 \%$ \\
\hline total & 93 & & 1162 & & 25 & \\
\hline
\end{tabular}

En d'autres endroits où le seigneur est canadien-français, la grande majorité des terres, que les populations soient mixtes ou presque uniquement anglophones, ont une étendue moyenne qui se rapproche de 90 arpents. Au lac Beauport, à Valcartier et dans Lotbinière, à St-Gilles et à St-Sylvestre, cette tendance est visible.

\begin{tabular}{lrrrrrrrr} 
arpents & Lac Beauport & \multicolumn{2}{c}{ Valcartier } & \multicolumn{2}{c}{ St-Gilles } & \multicolumn{2}{c}{ St-Sylvestre } \\
$0-50$ & 14 & $9 \%$ & 13 & $11 \%$ & 7 & $10 \%$ & 4 & $1 \%$ \\
$51-100$ & 124 & $82 \%$ & 78 & $66 \%$ & 32 & $50 \%$ & 154 & $65 \%$ \\
$101-200$ & 11 & $7 \%$ & 18 & $15 \%$ & 19 & $29 \%$ & 56 & $23 \%$ \\
201 et plus & 1 & - & 9 & $7 \%$ & 6 & $9 \%$ & 21 & $8 \%$ \\
\hline total & 150 & & 118 & & 64 & & 235 &
\end{tabular}

La caractéristique principale des localités de colonisation récente réside dans le très faible pourcentage de ceux qui ont des terres ayant 50 arpents et moins. Dans ces endroits où les cultivateurs sont la masse de la population, le morcellement de la propriété est à peine commencé. Mais l'étendue moyenne de la propriété y varie selon les traditions prévalant dans l'un ou l'autre des groupes ethniques. A première vue, les paroisses du comté de Saguenay semblent appartenir à ce groupe: seulement 
$10 \%$ des exploitants ont 50 arpents de terre et moins; mais ces anciennes paroisses, qui échappent encore au mouvement vers la fragmentation de la propriété foncière, vivent ou ont peutêtre vécu l'expérience d'un certain regroupement de la propriété.

Peut-on parler ici de résistance à la désintégration de la propriété foncière. Seules des études plus poussées le diraient.

\begin{tabular}{crr}
$\begin{array}{c}\text { arpents } \\
0-50\end{array}$ & 121 & $10 \%$ \\
$51-100$ & 469 & $40 \%$ \\
$101-200$ & 412 & $35 \%$ \\
201 et plus & 146 & $12 \%$ \\
\hline total & 1148
\end{tabular}

Il est d'autres groupes de paroisses anciennes qui échappent plus ou moins à la poussée vers la subdivision des fermes. Ainsi les paroisses du comté de Portneuf et les paroisses St-Antoinede-Tilly, Ste-Croix et St-Louis-de-Lotbinière présentent une physionomie assez semblable.

\begin{tabular}{ccccc} 
arpents & \multicolumn{2}{c}{ Lotbinière } & \multicolumn{2}{c}{ Portneuf } \\
$0-50$ & 149 & $16 \%$ & 326 & $18 \%$ \\
$51-100$ & 402 & $43 \%$ & 582 & $33 \%$ \\
$101-200$ & 256 & $27 \%$ & 624 & $36 \%$ \\
201 et plus & 113 & $12 \%$ & 191 & $11 \%$ \\
\hline total & 920 & & 1723
\end{tabular}

Les tendances à la subdivision et à la concentration des terres ne s'excluent pas. Les deux peuvent s'exprimer de différentes façons dans les seigneuries. Selon les lieux, l'une ou l'autre paraît l'emporter. En d'autres endroits, les deux s'affirment en même temps. Dans les paroisses de Beaumont, de St-Michel, de St-Charles et de St-Vallier et dans celles du comté de Lislet, ces deux forces semblent jouer à des degrés divers.

\begin{tabular}{lrrrr} 
arpents & \multicolumn{2}{c}{ Bellechasse } & \multicolumn{2}{c}{ Lislet } \\
$0-50$ & 260 & $28 \%$ & 260 & $22 \%$ \\
$51-100$ & 285 & $31 \%$ & 278 & $24 \%$ \\
$101-200$ & 294 & $32 \%$ & 381 & $33 \%$ \\
201 et plus & 72 & $7 \%$ & 214 & $18 \%$ \\
\hline total & 911 & & 1133
\end{tabular}

Dans un cas, le morcellement de la terre est l'élément le plus frappant du paysage rural et, dans l'autre, le phénomène de la concentration attire davantage l'attention. Il est évident que le 
paysan ne reste pas impassible devant les forces qui provoquent la désintégration des patrimoines. Rappelons ici que le comté de Lislet renferme, avec l'île d'Orléans, le plus fort pourcentage de non-propriétaires. Le propriétaire de terre est donc obligé de soustraire de son domaine de petites parcelles à des fins locatives.

De l'autre côté du fleuve, à l'île d'Orléans, sur la côte de Beaupré et à Charlesbourg, la même situation à quelques nuances près prévaut.

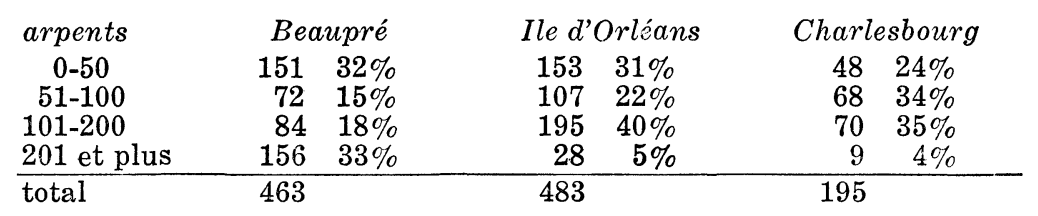

Sur la côte de Beaupré, la fragmentation et la concentration agissent puissamment, tandis qu'à l'île d'Orléans et à Charlesbourg, les efforts pour maintenir des unités rentables paraissent beaucoup plus ardus. Rappelons qu'à ces derniers endroits le pourcentage des cultivateurs est de $75 \%$ et $66 \%$ respectivement; celui des non-propriétaires est de $41 \%$ et $8 \%$.

Dans d'autres paroisses des environs de Québec, le pourcentage des détenteurs de parcelles ayant 50 arpents et moins s'accroît considérablement: $38 \%$ pour Beauport, l'Ancienne-Lorette et St-Ambroise. Le contraste est frappant avec la Beauce, région qui a maintenant atteint un seuil au-delà duquel la tendance vers le démembrement l'emporte: le pourcentage des possesseurs de plus de 200 arpents y est particulièrement bas.

\begin{tabular}{crrrrrr} 
arpents & Environs de Québec & \multicolumn{2}{c}{ Ste-Marie } & \multicolumn{2}{c}{ Ste-Claire } \\
$0-50$ & 151 & $38 \%$ & 170 & $20 \%$ & 97 & $24 \%$ \\
$51-100$ & 130 & $32 \%$ & 480 & $57 \%$ & 243 & $60 \%$ \\
$101-200$ & 99 & $25 \%$ & 158 & $18 \%$ & 55 & $13 \%$ \\
201 et plus & 16 & $4 \%$ & 24 & $2 \%$ & 6 & $2 \%$ \\
\hline total & 396 & & & 832 & & \multicolumn{2}{c}{401}
\end{tabular}

Le comté de Dorchester, la paroisse St-Gervais, celle de Rivière-du-Loup et le comté de Kamouraska sont les endroits où le processus du morcellement de la terre est le plus fortement engagé. A Pointe-Lévy, le pourcentage des 50 arpents et moins atteint $48 \%$, à St-Louis et à Rivière-Ouelle, il est de $43 \%$ et, à Ste-Anne-de-la-Pocatière, il monte à $50 \%$. 


\begin{tabular}{|c|c|c|c|c|}
\hline arpents & \multicolumn{2}{|c|}{ Dorchester et St-Gervais } & \multicolumn{2}{|c|}{ Kamouraska et Rivière-du-Loup } \\
\hline $\begin{array}{l}0-50 \\
51-100\end{array}$ & $\begin{array}{l}624 \\
894\end{array}$ & $\begin{array}{l}30 \% \\
44 \%\end{array}$ & $\begin{array}{r}716 \\
730\end{array}$ & $\begin{array}{l}37 \% \\
38 \%\end{array}$ \\
\hline $101-200$ & 409 & $20 \%$ & 328 & $17 \%$ \\
\hline 201 et plus & 92 & $4 \%$ & 118 & $6 \%$ \\
\hline total & 2019 & & 1892 & \\
\hline
\end{tabular}

Cette statistique, parce qu'elle se fonde sur les indications du rec nsement, met bien en évidence la résistance de la paysannerie au morcellement de la terre dont les conséquences économiquєs étaient particulièrement graves dans les circonstances. Par contre elle tend à minimiser l'ampleur réelle de la fragmentation de la propriété foncière. En effet les responsables locaux du recensement omettent à des degrés divers de mentionner l'étendue de la terre pour les parcelles les plus petites. Ces lacunes varient d'une paroisse à l'autre en certains cas et d'une région à l'autre. Ainsi le pourcentage de ceux qui résident sur des terres ayant 50 arpents et moins est un minimum. Ces écarts sont les suivants :

\begin{tabular}{|c|c|c|c|c|c|}
\hline $\begin{array}{l}\text { Beauce } \\
\text { Lotbinière } \\
\text { Dorchester } \\
\text { Bellechasse }\end{array}$ & $\begin{array}{l}5 \% \\
8 \% \\
17 \% \\
10 \%\end{array}$ & $\begin{array}{l}\text { Lislet } \\
\text { Kamouraska } \\
\text { Rimouski } \\
\text { Saguenay }\end{array}$ & $\begin{array}{l}33 \% \\
17 \% \\
12 \% \\
14 \%\end{array}$ & $\begin{array}{l}\text { Côte de Beaupré } \\
\text { Ile d'Orléans } \\
\text { Environs de Québec } \\
\text { Portneuf }\end{array}$ & $\begin{array}{l}13 \% \\
32 \% \\
37 \% \\
17 \%\end{array}$ \\
\hline
\end{tabular}

Il est vrai que la plupart de ces détenteurs de petites parcelles, qu'ils soient journaliers, artisans ou parfois même cultivateurs, habitent dans les villages; il n'en reste pas moins qu'une assez forte proportion d'entre eux résident dans la zone agricole. Une statistique, qui comble les lacunes du recensement, fait davantage ressortir les contrastes du territoire quant au morcellement et à la concentration des terres.

Ainsi, dans le comté de Lislet, sur l'île d'Orléans et sur la côte de Beaupré, l'existence de ces deux tendances contraires ne fait pas de doute. Le faible pourcentage de ceux qui ont des terres dont l'étendue varie entre 51 et 100 arpents, indique la vigueur de ces oppositions.

$\begin{array}{cccr}\text { arpents } & \text { Ile d'Orléans } & \text { Beaupré } & \text { Lislet } \\ 0-50 & 52 \% & 41 \% & 48 \% \\ 51-100 & 15 \% & 13 \% & 16 \% \\ 101-200 & 27 \% & 15 \% & 22 \% \\ 201 \text { et plus } & 3 \% & 29 \% & 12 \%\end{array}$

Dans les environs de Québec, dans Dorchester, Bellechasse et Kamouraska, le courant vers la fragmentation des terres sem- 
ble triompher réellement. Ce qui ne veut pas dire que les efforts en vue du regroupement soient inexistants.

$\begin{array}{ccccc} & \text { Environs } & & & \\ \text { arpents } & \text { de Québec } & \text { Dorchester } & \text { Bellechasse } & \text { Kamouraska } \\ 0-50 & 59 \% & 41 \% & 36 \% & 48 \% \\ 51-100 & 21 \% & 37 \% & 32 \% & 32 \% \\ 101-200 & 16 \% & 16 \% & 24 \% & 14 \% \\ 201 \text { et plus } & 2 \% & 4 \% & 5 \% & 5 \%\end{array}$

Ailleurs le morcellement de la terre s'opère encore modérément. Dans la Beauce cependant le groupe de ceux qui possèdent plus de 100 arpents de terre est réduit. A Ste-Marie-de-Beauce, si on excepte le seigneur, seulement trois cultivateurs et un marchand anglophone ont des terres excédant 300 arpents. A St-François, quatre Anglophones, dont W. Pozer qui récolte 3000 minots de pommes de terre, appartiennent à la même catégorie. A St-Joseph et à Ste-Claire, ce groupe ne comprend que deux personnes dont un Anglophone. Dans Lotbinière, Portneuf et Saguenay, les spéculateurs sont plus actifs. Parmi eux, les Anglophones se situent favorablement, qu'ils soient seigneurs, marchands, bourgeois ou simples cultivateurs. A Petite-Rivière StFrançois, 14\% des propriétaires ont plus de 1000 arpents.

$\begin{array}{cccccc}\text { arpents } & \text { Lotbinière } & \text { Portneuf } & \text { Saguenay } & \text { Ste-Marie } & \text { Ste-Claire } \\ 0-50 & 20 \% & 33 \% & 25 \% & 23 \% & 28 \% \\ 51-100 & 43 \% & 27 \% & 34 \% & 55 \% & 56 \% \\ 101-200 & 24 \% & 29 \% & 30 \% & 18 \% & 13 \% \\ 201 \text { et plus } & 10 \% & 9 \% & 10 \% & 2 \% & 1 \%\end{array}$

Malgré les mouvements qui agitent la propriété foncière dans le district de Québec, l'exploitation moyenne, celle qui occupe 70 ou 90 arpents au lieu de 56, est encore très répandue. N'empêche que cet équilibre est précaire. La décennie qui débute allait accentuer les tendances vers la fragmentation.

La dimension de la terre, la nature et la richesse du sol, les techniques, la proximité de la ville et, généralement, les possibilités de contacts avec les marchés influent sur la situation de l'agriculture. Les mutations qui se produisent dans l'un ou l'autre domaine déterminent des changements dans la structure de la production. De même les rapports entre la croissance démographique et les quantités de terres disponibles, tout comme la politique des seigneurs en matière de concessions de terres, ont un impact direct sur la condition de l'agriculteur. C'est dans ce contexte mouvant que s'expliquent les transformations structurelles de l'agriculture bas-canadienne durant la première moitié du XIXe siècle. Le district de Québec n'échappe pas à cette 
évolution que traduit le recensement de 1831 et qui s'accélère par la suite. Ce recensement de 1831, année de récolte exceptionnelle, et celui de 1842, fait en année médiocre, traduisent d'une façon frappante la révolution agricole.

\section{ÉVENTAIL DE LA PRODUCTION: PRINCIPAUX PRODUITS (minots)}

\begin{tabular}{|c|c|c|c|c|c|c|}
\hline & blé & $\begin{array}{c}1831 \\
\text { avoine }\end{array}$ & "patates" & blé & $\begin{array}{c}1846 \\
\text { avoine }\end{array}$ & "patates" \\
\hline Beauce & 55739 & 37385 & 124582 & 3491 & 134472 & 137809 \\
\hline $\begin{array}{l}\% \text { de la récolte } \\
\text { Lotbinière }\end{array}$ & $\begin{array}{r}25 \% \\
59392\end{array}$ & $\begin{array}{r}17 \% \\
43494\end{array}$ & $\begin{array}{r}57 \% \\
107178\end{array}$ & $\begin{array}{r}1 \% \\
3890\end{array}$ & $\begin{array}{r}48 \% \\
185444\end{array}$ & $\begin{array}{r}49 \% \\
166406\end{array}$ \\
\hline \% de la récolte & $28 \%$ & $20 \%$ & $50 \%$ & $1 \%$ & $52 \%$ & $\begin{array}{r}46 \% \\
105705\end{array}$ \\
\hline $\begin{array}{l}\text { Dorchester } \\
\% \text { de la récolte }\end{array}$ & $\begin{array}{r}43575 \\
20 \%\end{array}$ & $\begin{array}{r}66030 \\
31 \%\end{array}$ & $\begin{array}{r}101459 \\
48 \%\end{array}$ & $\begin{array}{r}1048 \\
.6 \%\end{array}$ & $\begin{array}{r}144014 \\
57 \%\end{array}$ & $\begin{array}{r}100700 \\
42 \%\end{array}$ \\
\hline Bellechasse & 104619 & 140540 & 217321 & 8099 & 204915 & 207609 \\
\hline $\begin{array}{l}\% \text { de la récolte } \\
\text { Lislet }\end{array}$ & $\begin{array}{r}22 \% \\
172671\end{array}$ & $\begin{array}{r}30 \% \\
73265\end{array}$ & $\begin{array}{r}46 \% \\
109844\end{array}$ & $\begin{array}{r}1 \% \\
9847\end{array}$ & $\begin{array}{r}48 \% \\
199437\end{array}$ & $\begin{array}{r}49 \% \\
176802\end{array}$ \\
\hline \% de la récolte & $\begin{array}{r}1726 \% 1 \\
48 \%\end{array}$ & $\begin{array}{r}73200 \\
20 \%\end{array}$ & $\begin{array}{r}109844 \\
30 \%\end{array}$ & $\begin{array}{r}9847 \\
2 \%\end{array}$ & $51 \%$ & $45 \%$ \\
\hline Kamouraska & 168930 & 68391 & 97571 & 5704 & 110667 & 181215 \\
\hline$\%$ de la récolte & $50 \%$ & $20 \%$ & $29 \%$ & 101 & $37 \%$ & \\
\hline venay & 66394 & 28564 & 93156 & 7557 & 25674 & 86694 \\
\hline récolte & $35 \%$ & $15 \%$ & & & $21 \%$ & $72 \%$ \\
\hline oré & 39693 & 38073 & 49282 & 6659 & 71034 & 59878 \\
\hline la rócoltt & & & & & $51 \%$ & $43 \%$ \\
\hline Ile d'Orléans & 33094 & 88786 & 56728 & 3760 & 64816 & 83637 \\
\hline le la récolte & & & & $2 \%$ & $42 \%$ & $54 \%$ \\
\hline . de Québec & 21816 & 112214 & 247312 & 1621 & 146340 & 303475 \\
\hline la récolte & & $29 \%$ & & & & \\
\hline & 30 & 80030 & 24827 & 3075 & 129557 & 179541 \\
\hline de la récolte & & $0 \Omega \Omega_{1}$ & $52 \%$ & $.9 \%$ & $41 \%$ & $57 \%$ \\
\hline
\end{tabular}

Ces statistiques, bien qu'elles soient incomplètes, situent le recensement de 1831 dans la perspective d'un changement de nature dans l'agriculture et expriment les contrastes entre les différentes régions du district de Québec.

Ce tableau fait d'abord apparaître une région recouvrant les comtés de Lislet et de Kamouraska où, malgré une croissance très lente de la production à partir du début du XIXe siècle, le blé a maintenu sa suprématie dans la récolte. Les statistiques sur la dîme pour la paroisse de Lislet ${ }^{2}$, très inadéquates en ce qui concerne la production de la pomme de terre, font état de cette évolution. A St-Roch-des-Aulnaies et dans la paroisse de Lislet, la récolte moyenne par producteur est en 1831 de 198 et

2 Fernand Ouellet, Eléments d'histoire sociale du Bas-Canada. Collection Histoire - (Les Cahiers du Québec, 1972. Hurtubise HMH, Ltée, Montréal), 74-78. La dîme sur la pomme de terre n'était pas légale. Le don était volontaire. 
192.5 minots de blé. Il est certain que la richesse du terroir explique en partie la survivance du blé comme production principale. Pourtant les grosses paroisses de la plaine de Montréal étaient dans la même situation. Il semble que la tendance à la concentration des terres ou la résistance à la fragmentation aient joué un rôle à cet égard. Car l'importance du blé dans la récolte est presque toujours liée à l'étendue de la terre. Le comté de Kamouraska paraît échapper à la règle, mais là encore, la production moyenne par ferme est plus élevée dans les paroisses où le morcellement est le moins engagé. Les paroisses RivièreOuelle et St-Louis de Kamouraska sont les meilleurs exemples.

\begin{tabular}{|c|c|c|c|c|}
\hline \multirow{2}{*}{$\begin{array}{c}\text { minots } \\
0-50 \\
51-100 \\
101-200 \\
201 \text { et plus }\end{array}$} & \multicolumn{2}{|c|}{ Lislet } & \multicolumn{2}{|c|}{ Kamourastia } \\
\hline & $\begin{array}{l}243 \\
193 \\
326 \\
241\end{array}$ & $\begin{array}{l}24 \% \\
19 \% \\
32 \% \\
24 \%\end{array}$ & $\begin{array}{l}452 \\
270 \\
357 \\
241\end{array}$ & $\begin{array}{l}34 \% \\
20 \% \\
27 \% \\
18 \%\end{array}$ \\
\hline total & 1003 & & 1320 & \\
\hline
\end{tabular}

La résistance aux pressions vers le morce!lement de la terre avait donc pour objet le maintien d'un type d'agriculture fondé sur le blé. Mais peut-on dire que les cultivateurs de cette région ont cherché, à partir de la seconde moitié du XVIIIe siècle, à commercialiser leurs exploitations? Dans ces deux comtés, la production du blé, si on tient compte du nombre des consommateurs locaux, n'est pas déficitaire dans la grande majorité des paroisses. Les surplus exportables à l'extérieur du territoire étaient plutôt minimes et dépendaient par surcroît de la qualité de la production. Il n'en reste pas moins que le marché local était assez considérable. Ainsi, dans la paroisse de Lislet, les producteurs de blé ne représentent que $49 \%$ des chefs de famille alors que $30 \%$ des producteurs de blé récoltent plus de 200 minots. Il existe dans un grand nombre de ces paroisses des minorités assez importantes de cultivateurs qui écoulent leurs surplus dans le voisinage. Ceux-ci ne pratiquent pas vraiment une agriculture de subsistance basée sur la recherche du minimum vital. Même si les rendements sont plutôt bas et les techniques le plus souvent déficientes, ils possèdent une certaine sensibilité au marché qui n'implique pas nécessairement une véritable commercialisation de l'exploitation agricole. Pour l'élite des cultivateurs, pour les paysans ayant des surplus plus ou moins modestes et pour ceux, plus nombreux, voués à l'auto-suffisance, la décennie 1830-40 allait être particulièrement brutale. Les mauvaises récoltes, le morcellement de la terre, l'épuisement des sols et la mouche à blé entraînent une modification radicale de la structure de la 
production et, en même temps, une chute des revenus. L'agriculture nouvelle s'établit sur l'avoine et sur la pomme de terre. Le cultivateur devient un acheteur de farine. Cette évolution apparaît assez bien dans la comptabilité d'un marchand de St-Rochdes-Aulnaies: le blé cesse de faire partie des paiements en nature alors que les paysans, acheteurs de farine, apportent de l'avoine et des pommes de terre en échange. Dans la mesure où le troc est encore en vigueur, ces réalités sont observables.

Il est d'autres endroits où les paysans avaient réussi à empêcher un déclin trop radical de la production du blé. Dans la plupart de ces paroisses, la position relative du froment dans la récolte avait commencé à s'affaiblir depuis longtemps. Même si, dans cette région, le blé a décliné au profit de la pomme de terre et de l'avoine, il conserve encore une importance considérable pour la paysannerie. Il est vrai que d'un groupe de paroisses à l'autre la qualité du sol varie considérablement, mais des groupes de paysans avaient réussi à étendre leurs domaines, ce qui favorise le maintien de la culture du froment. Dans quelques paroisses, celle-ci prédomine encore.

\section{ÉVENTAIL DE LA PRODUCTION DU BLÉ}

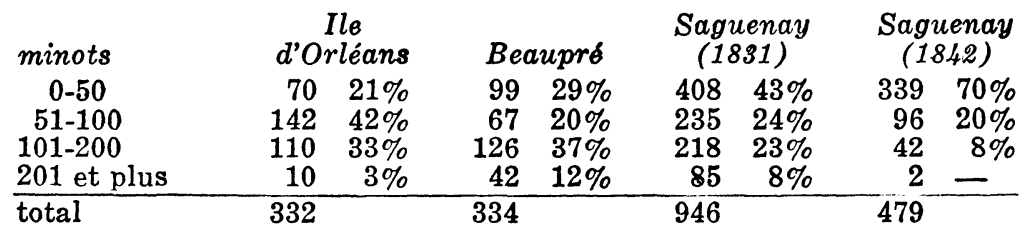

Dans cette région, les paysans qui ont des surplus, parviennent à peine à rencontrer les besoins des consommateurs du territoire. L'île d'Orléans était probablement déficitaire: 99 minots par producteur mais 47 par famille. Dix ans plus tard, le blé n'est plus qu'une production secondaire: le nombre de ceux qui l'ensemencent ainsi que la production par ferme ont décliné. Le cas de l'Ile-aux-Coudres est intéressant à ce point de vue.

\begin{tabular}{|c|c|c|c|c|c|c|}
\hline \multicolumn{7}{|c|}{ PRODUCTION AGRICOLE } \\
\hline minots & blé & $\begin{array}{c}1831 \\
\text { avoine }\end{array}$ & "patates" & blé & $\begin{array}{c}1842 \\
\text { avoine }\end{array}$ & "patates" \\
\hline $\begin{array}{c}0-50 \\
51-100 \\
101-200 \\
201 \text { et plus }\end{array}$ & $\begin{array}{rl}12 & 18 \% \\
18 & 27 \% \\
29 & 43 \% \\
7 & 10 \%\end{array}$ & $\begin{array}{rr}51 & 80 \% \\
10 & 15 \% \\
2 & 3 \% \\
0 & -\end{array}$ & $\begin{array}{rr}15 & 21 \% \\
25 & 36 \% \\
26 & 37 \% \\
3 & 4 \%\end{array}$ & 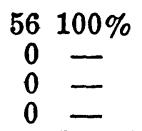 & $\begin{array}{rl}42 & 53 \% \\
17 & 21 \% \\
10 & 12 \% \\
9 & 11 \%\end{array}$ & $\begin{array}{rl}9 & 11 \% \\
15 & 19 \% \\
34 & 44 \% \\
18 & 23 \%\end{array}$ \\
\hline otal & 66 & 63 & 69 & 56 & 78 & 76 \\
\hline
\end{tabular}


Ce changement brutal ne peut s'expliquer par le simple contraste entre une bonne et une mauvaise année. La mutation est fondamentale en ce sens qu'elle touche la structure même de la production. A court terme elle n'a certes pas permis d'enrichir les habitants de l'endroit qui ont aussi vu leurs troupeaux diminuer.

TROUPEAUX EN 1831 ET EN 1842

\begin{tabular}{lrrrrrrrr} 
& \multicolumn{3}{c}{ bêtes } & \multicolumn{4}{c}{ b } \\
nombre & \multicolumn{2}{c}{ cornes } & \multicolumn{2}{c}{ porcs } & \multicolumn{2}{c}{ à cornes } & \multicolumn{2}{c}{ porcs } \\
5 et & 12 & $16 \%$ & 10 & $13 \%$ & 25 & $30 \%$ & 29 & $34 \%$ \\
$6-10$ & 31 & $42 \%$ & 28 & $38 \%$ & 41 & $50 \%$ & 40 & $47 \%$ \\
$11-15$ & 21 & $28 \%$ & 25 & $34 \%$ & 12 & $14 \%$ & 15 & $17 \%$ \\
$16-20$ & 7 & $9 \%$ & 8 & $11 \%$ & 3 & $3 \%$ & 1 & $1 \%$ \\
21 et plus & 2 & $2 \%$ & 1 & $1 \%$ & 1 & $1 \%$ & 0 & - \\
\hline total & 73 & & 72 & & & 82 & & 85
\end{tabular}

Cet exemple, tellement caractéristique de la mutation brutale des années 1830-40 dans les localités où le froment restait une céréale forte, éclaire aussi la situation des régions où le même processus était en 1831 plus avancé.

Partout ailleurs dans le district de Québec, les minorités paysannes, disposant de surplus négociables, ont tendance à fondre. Ces régions importent du blé pour la consommation locale. Les comtés de Lotbinière, Bellechasse et Portneuf ne se suffisent plus. Le groupe de ceux qui produisent plus de 100 minots de blé varie entre 15 et $22 \%$ des producteurs de blé. Ceux-ci ne parviennent pas à satisfaire à la demande des producteurs locaux déficitaires et des autres consommateurs.

\section{ÉVENTAIL DE LA PRODUCTION DU BLÉ EN 1831}

\begin{tabular}{|c|c|c|c|c|c|c|c|c|}
\hline \multirow{3}{*}{$\begin{array}{c}\text { minots } \\
0-50 \\
51-100\end{array}$} & \multicolumn{2}{|c|}{ Lotbinière } & \multicolumn{2}{|c|}{ Bellechasse } & \multicolumn{2}{|c|}{$\begin{array}{c}\text { Portneuf } \\
(1831)\end{array}$} & \multicolumn{2}{|c|}{$\begin{array}{c}\text { Portneuf } \\
\text { (1842) }\end{array}$} \\
\hline & $\begin{array}{l}556 \\
238\end{array}$ & $57 \%$ & $\begin{array}{l}527 \\
368\end{array}$ & $45 \%$ & 581 & $53 \%$ & 198 & $96 \%$ \\
\hline & 153 & 15 & 242 & 20 & $\begin{array}{l}000 \\
159\end{array}$ & $\begin{array}{l}50 \\
14\end{array}$ & 2 & $\underline{4}$ \\
\hline et plus & 1 & & 31 & $2 \%$ & 13 & $1 \%$ & 0 & - \\
\hline total & 965 & & 1168 & & 1091 & & 206 & \\
\hline
\end{tabular}

Sur les autres portions du territoire, il est possible de parler d'effondrement de la production du froment. Il est vrai que les comtés de Lotbinière, de Portneuf, de Rimouski et les environs de Québec possèdent des minorités plus ou moins nombreuses de cultivateurs anglophones qui ont tendance à accorder peu de valeur au froment dans leur récolte; mais le phénomène qu'ex- 
priment les chiffres a une portée générale. Le paysan canadienfrançais lui-même est entraîné de gré ou par la force des choses à modeler la structure de sa production sur celle des Britanniques. Quelques exemples illustreront cet intérêt limité des Anglophones pour le blé.

\section{ÉVENTAIL DE LA PRODUCTION DU BLÉ}

\begin{tabular}{|c|c|c|c|c|c|c|}
\hline \multirow{3}{*}{$\begin{array}{c}\text { minots } \\
0-50 \\
51-100\end{array}$} & \multicolumn{2}{|c|}{ Leeds (canton) } & \multicolumn{2}{|c|}{$\begin{array}{l}\text { St-Sylvestre } \\
\text { (Lotbinière) }\end{array}$} & \multicolumn{2}{|c|}{$\begin{array}{l}\text { Ste-Catherine } \\
\text { (Portneuf) }\end{array}$} \\
\hline & 23 & $48 \%$ & 153 & $90 \%$ & 43 & $100 \%$ \\
\hline & 17 & $36 \%$ & 14 & $8 \%$ & 0 & - \\
\hline $101-200$ & 6 & $12 \%$ & 2 & $1 \%$ & 0 & - \\
\hline 201 et plus & 1 & $2 \%$ & 0 & - & 0 & - \\
\hline total & 47 & & 169 & & 43 & \\
\hline
\end{tabular}

Dans les environs de Québec et dans le comté de Rimouski, les Anglophones sont suffisamment nombreux pour influencer l'équilibre de la production; mais, dans la Beauce et Dorchester, leur présence parmi les cultivateurs est minimale.

ÉVENTAIL DE LA PRODUCTION DU BLÉ

\begin{tabular}{crrrrrrrr} 
& & & & & \multicolumn{2}{c}{ Environs de } \\
minots & Beauce & \multicolumn{2}{c}{ Dorchester } & \multicolumn{2}{c}{ Rimouski } & \multicolumn{2}{c}{ Québec } \\
$0-50$ & 742 & $81 \%$ & 630 & $67 \%$ & 657 & $68 \%$ & 354 & $76 \%$ \\
$51-100$ & 142 & $15 \%$ & 222 & $23 \%$ & 194 & $20 \%$ & 94 & $20 \%$ \\
$101-200$ & 22 & $2 \%$ & 79 & $8 \%$ & 93 & $9 \%$ & 14 & $3 \%$ \\
201 et plus & 4 & - & 7 & - & 21 & $2 \%$ & 1 & - \\
\hline total & 910 & & 938 & & 965 & & 463
\end{tabular}

Ainsi, en 1831, une seule région, recouvrant en gros les comtés de Lislet et de Kamouraska, maintient la suprématie traditionnelle du blé dans la récolte et produit assez pour les besoins de son territoire. Le cultivateur qui a des surplus les écoule surtout sur le marché local. Peut-être la qualité de son produit estelle en cause ? Il est possible aussi que les seigneurs et les curés aient envoyé leurs redevances en nature au marché de Québec. De Charlevoix à l'île d'Orléans, la production en cette année de récolte exceptionnelle suffit certainement à nourrir la population locale. Partout ailleurs dans le district, même si des minorités paysannes de plus en plus restreintes, des seigneurs et des curés ont des surplus négociables, la production est plus ou moins déficitaire selon les endroits. Dans son ensemble, le district de Québec n'assure pas en entier la subsistance de sa population. En 1842 et bien avant, il est devenu un très gros importateur de farine. Il évident que les régions qui, encore en 1831 
produisaient du blé en abondance, sont celles qui souffrent davantage de cette mutation.

Somme toute, malgré l'expansion de la demande sur le marché impérial et sur le marché local en raison de la diversification des occupations, la paysannerie ne peut, à partir du début du XIXe siècle, maintenir la production à la hausse. Le marché extérieur est de plus en plus ravitaillé par le Haut-Canada et les Etats-Unis. En 1831, les producteurs les plus actifs vendent aux consommateurs locaux. Mais, comme le déclin s'opère d'une façon inégale selon les régions, le ravitaillement des zones déficitaires se fait à partir des villes où se trouvent les importateurs de céréales. Le blé, fondement d'une économie de subsistance et instrument de commercialisation éventuelle de l'agriculture, ne joue plus son rôle. Pourtant le paysan moyen cherche obstinément à en produire. Des techniques agricoles déficientes, des sols souvent inadéquats, des exploitations trop petites engendrent la crise du blé.

Dans ces conditions, le revenu paysan doit s'alimenter à d'autres sources. L'avoine qui est aussi une production traditionnelle liée à la subsistance des animaux de la ferme, suscite davantage qu'autrefois l'intérêt de la paysannerie. Comme compensation à la faillite du froment, celle-ci est forcée, pour des raisons de subsistance, à augmenter le nombre des animaux de la ferme et en même temps sa production d'avoine. Le paysan ne semble pas encore apprécier le "gruau" qui fait le délice de bien des Anglophones. Mais nombreux sont les cultivateurs qui portent attention aux besoins du marché en ce domaine. La croissance de la ville et le commerce du bois stimulent le producteur local. La nature du sol et les facilités de communications avec le marché urbain sont les principaux facteurs de croissance en ce domaine. Dans certaines régions, les gros producteurs d'avoine constituent un pourcentage important de la masse des agriculteurs. L'avoine est surtout une production locale pour un marché local.

ÉVENTAIL DE LA PRODUCTION DE L'AVOINE

\begin{tabular}{|c|c|c|c|c|c|c|}
\hline minots & $\begin{array}{l}\text { Belle- } \\
\text { chasse }\end{array}$ & Beaupré & $\begin{array}{c}\text { Ile } \\
\text { d'Orléans }\end{array}$ & $\begin{array}{c}\text { Environs } \\
\text { de } Q .\end{array}$ & Portneuf & $\begin{array}{c}\text { Portneuf } \\
(1.842)\end{array}$ \\
\hline $\begin{array}{c}0-50 \\
51-100\end{array}$ & $\begin{array}{ll}451 & 37 \% \\
307 & 25 \%\end{array}$ & $\begin{array}{rl}100 & 30 \% \\
95 & 29 \%\end{array}$ & $\begin{array}{r}7723 \% \\
10332 \%\end{array}$ & $\begin{array}{l}26833 \% \\
21125 \%\end{array}$ & $\begin{array}{ll}391 & 28 \% \\
382 & 28 \%\end{array}$ & $\begin{array}{ll}316 & 30 \% \\
259 & 24 \%\end{array}$ \\
\hline $101-200$ & $31626 \%$ & $9529 \%$ & $11335 \%$ & $21426 \%$ & $43231 \%$ & $29128 \%$ \\
\hline 201 et plus & $1149 \%$ & $3611 \%$ & $28 \quad 8 \%$ & $11914 \%$ & $15811 \%$ & $17316 \%$ \\
\hline otal & 1188 & 326 & 321 & 812 & 1363 & 1039 \\
\hline
\end{tabular}


Dans toutes ces régions, la production de l'avoine surpasse celle du blé. Son expansion apparaît comme une des solutions de rechange. En 1842, l'avoine est même devenue la céréale principale sur la côte de Beaupré. Il est clair cependant que cette évolution ne comportait pas une augmentation du revenu paysan puisque le prix de l'avoine était environ la moitié de celui du blé.

Partout ailleurs, excepté dans Dorchester, l'avoine a conservé l'importance relative qu'elle avait eue dans le passé. Les habitants de Dorchester, probablement déçus par les rendements décroissants du blé, avaient accru leur production d'avoine à cause de la demande créée par l'exploitation forestière. Au total il n'y a que quatre comtés où le nombre des producteurs d'avoine l'emporte sur celui des producteurs de froment: Bellechasse, Dorchester, les environs de Québec, Portneuf.

\section{ÉVENTAIL DE LA PRODUCTION DE L'AVOINE}

\begin{tabular}{crrrrrrrr} 
minots & \multicolumn{2}{c}{ Lotbinière } & \multicolumn{2}{c}{ Dorchester } & \multicolumn{2}{c}{ Lislet } & \multicolumn{2}{c}{ Kamouraska } \\
$0-50$ & 514 & $57 \%$ & 509 & $51 \%$ & 522 & $58 \%$ & 441 & $58 \%$ \\
$51-100$ & 208 & $23 \%$ & 276 & $27 \%$ & 240 & $26 \%$ & 124 & $16 \%$ \\
$101-200$ & 146 & $16 \%$ & 175 & $17 \%$ & 117 & $13 \%$ & 117 & $15 \%$ \\
201 et plus & 27 & $3 \%$ & 37 & $3 \%$ & 21 & $2 \%$ & 75 & $9 \%$ \\
\hline total & 895 & & 997 & & 900 & & 757
\end{tabular}

La position relative de l'avoine dans Lislet et Kamouraska s'explique par la survivance d'une agriculture fondée sur le blé. Le gros producteur de froment est souvent un gros producteur d'avoine. Ailleurs le surplus d'avoine accompagne très souvent un surplus encore plus considérable de pommes de terre. En 1842, $d \in \mathrm{S}$ changements se sont produits à cet égard: dans Lislet, Dorchester et sur la côte de Beaupré, l'activité agricole tend à se concentrer davantage autour de la production de l'avoine. Il est cependant des endroits où la faiblesse de l'avoine accompagne surtout une stagnation générale de l'agriculture.

\section{ÉVENTAIL DE LA PRODUCTION DE L'AVOINE}

\begin{tabular}{lrrrrrrrr} 
& & & & & & \multicolumn{2}{c}{ Saguenay } \\
minots & Beauce & Rimouski & \multicolumn{2}{c}{ Saguenay } & \multicolumn{2}{c}{$(1842)$} \\
$0-50$ & 691 & $84 \%$ & 346 & $87 \%$ & 671 & $84 \%$ & 348 & $68 \%$ \\
$51-100$ & 94 & $11 \%$ & 36 & $9 \%$ & 104 & $13 \%$ & 101 & $20 \%$ \\
$101-200$ & 31 & $3 \%$ & 9 & $2 \%$ & 14 & $1 \%$ & 38 & $6 \%$ \\
201 et plus & 3 & - & 5 & $1 \%$ & 5 & - & 13 & $2 \%$ \\
\hline total & $\mathbf{8 1 9}$ & & 396 & & 794 & & 500 &
\end{tabular}


Le cas du Saguenay est quelque peu différent puisqu'il s'agit d'un endroit où le blé avait encore de fortes assises.

Les producteurs de pommes de terre surclassent en nombre ceux d'avoine et de blé: ceux-là représentent $73 \%$ des chefs de famille et ceux-ci 54 et $59 \%$ respectivement. Dans la perspective du déclin du blé en tant que base de la subsistance, la production de la pomme de terre d'abord restreinte à la nourriture des animaux puis utilisée dans l'alimentation des hommes par la multiplication des mauvaises récoltes prend son sens. A mesure que les récoltes de blé fléchissent ou cessent d'augmenter avec la population, les paysans sont forcés d'étendre la culture de la pomme de terre. Non seulement celle-ci est-elle moins exigeante pour les sols, mais elle peut se cultiver en quantités suffisantes sur des espaces restreints. Le morcellement de la terre, qui accélère l'épuisement du terroir, entraîne l'abandon progressif de la culture du blé et son remplacement par la pomme de terre. Celleci devient alors un objet d'attention sur les terres plus vastes de sorte qu'elle apparaît vite après 1815 l'un des principaux produits de la ferme. Pour l'immigrant anglophone, la pomme de terre fait spontanément figure de production principale, du moins au XIXe siècle. Dans le township de Leeds, la production moyenne par ferme est de 392 minots: dans les six autres cantons du comté de Mégantic, elle est de 261 minots. Sur l'île d'Orléans et sur la côte de Beaupré, les plus anciens centres de production de la pomme de terre de l'aire seigneuriale, ces moyennes sont de 152 et de 103 minots. Une comparaison entre le comté de Kamouraska, où le blé représente $50 \%$ de la récolte, et le comté de Mégantic, où la pomme de terre constitue $83 \%$ de la moisson, marque le contraste entre ces deux types d'agriculture.

\begin{tabular}{crrrr} 
ÉVENTAIL DE LA & PRODUCTION DE LA POMME DE TERRE \\
minots & Kamouraska & \multicolumn{2}{c}{ Mégantic } \\
$0-50$ & 749 & $54 \%$ & 7 & $3 \%$ \\
$51-100$ & 358 & $26 \%$ & 26 & $13 \%$ \\
$101-200$ & 196 & $14 \%$ & 60 & $30 \%$ \\
201 et plus & 70 & $5 \%$ & 107 & $53 \%$ \\
\hline total & 1373 & & 200
\end{tabular}

Le colon anglophone, qu'il s'établisse dans les endroits isolés, sans contacts aisés avec le marché ou près des villes, centre son activité sur la culture de la pomme de terre. Dans les paroisses seigneuriales où existent des minorités anglophones, la production 
par ferme de la "patate" est toujours plus élevée que dans le voisinage: à St-Gilles et à St-Sylvestre de Lotbinière cet écart est de 50 minots par ferme. A Ste-Catherine-de-Fossambault, comté de Portneuf, la production moyenne est de 267 minots contre 99 à Cap-Santé. La pomme de terre, à cause de l'existence d'un marché local important, est aussi un facteur de commercialisation de l'agriculture.

En 1831, la pomme de terre est la production principale dans toutes les régions, excepté dans Lislet et Kamouraska. L'agriculture canadienne-française tend donc à se modeler progressivement sur celle des Anglophones. Mais les objectifs d'une façon générale ne sont pas les mêmes. Les Canadiens français cherchent davantage à résoudre un problème de subsistance, alors que les Britanniques paraissent songer davantage au marché. Il y a là un contraste qui n'est pas également marqué sur tous les points du territoire. Il est certain que, dans la Beauce, Kamouraska, Rimouski et Saguenay, le niveau de la production est particulièrement bas dans l'ensemble.

ÉVENTAIL DE LA PRODUCTION DE LA POMME DE TERRE

\begin{tabular}{lrrrrrrrr} 
& \multicolumn{1}{c}{ Saguenay } \\
minots & \multicolumn{1}{c}{ Beauce } & \multicolumn{1}{c}{ Sagwenay } & \multicolumn{2}{c}{$(1842)$} & \multicolumn{2}{c}{ Rimouski } \\
$0-50$ & 553 & $55 \%$ & 534 & $52 \%$ & 182 & $29 \%$ & 593 & $57 \%$ \\
$51-100$ & 262 & $26 \%$ & 300 & $29 \%$ & 188 & $30 \%$ & 232 & $22 \%$ \\
$101-200$ & 124 & $12 \%$ & 160 & $15 \%$ & 178 & $28 \%$ & 155 & $15 \%$ \\
201 et plus & 50 & $5 \%$ & 31 & $3 \%$ & 78 & $12 \%$ & 53 & $5 \%$ \\
\hline total & 989 & & 1025 & & 626 & & 1033
\end{tabular}

Même si le recensement de 1842 recouvre mal le comté de Saguenay, la statistique exprime cependant la réalité: la chute du blé s'accompagne à cet endroit d'une montée de la production de la pomme de terre. La récolte d'avoine reste médiocre. Dans les endroits où des Anglophones œuvrent parmi la population canadienne-française, les contrastes entre les groupes ethniques sont visibles. Dans la Beauce, W. Pozer est le plus gros producteur de "patates" avec 3000 minots. A Matane, les deux groupes ethniques sont numériquement égaux: les Canadiens français produisent 98 minots de pommes de terre, entretiennent 2.2 bểtes à cornes et 4.3 porcs; de leur côté, les Anglophones récoltent 215 minots de pommes de terre par ferme et gardent 6.7 bêtes à cornes et 8.8 porcs.

Dans les comtés de Dorchester, Lislet, Lotbinière et sur la côte de Beaupré, les gros producteurs sont plus nombreux et les ventes sur le marché local beaucoup plus considérables. 
ÉVENTAIL DE LA PRODUCTION DE LA POMME DE TERRE

\begin{tabular}{ccccccccc} 
minots & \multicolumn{2}{c}{ Lotbinière } & \multicolumn{2}{c}{ Dorchester } & \multicolumn{2}{c}{ Lislet } & \multicolumn{2}{c}{ Beaupré } \\
$0-50$ & 419 & $36 \%$ & 445 & $37 \%$ & 352 & $32 \%$ & 218 & $45 \%$ \\
$51-100$ & 360 & $30 \%$ & 344 & $28 \%$ & 336 & $31 \%$ & 110 & $23 \%$ \\
$101-200$ & 271 & $23 \%$ & 282 & $23 \%$ & 276 & $25 \%$ & 93 & $19 \%$ \\
201 et plus & 112 & $9 \%$ & 118 & $9 \%$ & 109 & $10 \%$ & 54 & $11 \%$ \\
\hline total & 1162 & & 1189 & & 1073 & & 475
\end{tabular}

Les centres les plus importants de production de la pomme de terre se trouvent, si on excepte les townships et Bellechasse, à proximité de la ville de Québec. Le facteur distance avait sa signification mais il n'était pas le seul.

\begin{tabular}{|c|c|c|c|c|c|}
\hline minots & $\begin{array}{c}\text { Ile } \\
\text { d'Orléans }\end{array}$ & $\begin{array}{l}\text { Env. de } \\
\text { Québec }\end{array}$ & $\begin{array}{l}\text { Belle- } \\
\text { chasse }\end{array}$ & Portneuf & $\begin{array}{c}\text { Portneuf } \\
(1.842)\end{array}$ \\
\hline $\begin{array}{c}0-50 \\
51-100\end{array}$ & $\begin{array}{l}9021 \% \\
8720 \%\end{array}$ & $\begin{array}{l}31827 \% \\
26323 \%\end{array}$ & $\begin{array}{l}40729 \% \\
33124 \%\end{array}$ & $\begin{array}{l}40925 \% \\
51832 \%\end{array}$ & $\begin{array}{ll}371 & 30 \% \\
373 & 30 \%\end{array}$ \\
\hline $101-200$ & $16037 \%$ & $26423 \%$ & $38528 \%$ & $420 \quad 26 \%$ & $31328 \%$ \\
\hline 201 et plus & $8720 \%$ & $29125 \%$ & $248 \quad 18 \%$ & $23614 \%$ & $15212 \%$ \\
\hline total & 424 & 1136 & 1371 & 1583 & 1209 \\
\hline
\end{tabular}

En général, la montée de la production de la pomme de terre accompagne la défaillance de la production du blé et sert à résoudre le problème de la subsistance. Il est néanmoins des minorités de cultivateurs qui agissent en vue d'un profit possible. Ces minorités dont la dimension varie d'une région à l'autre ne pratiquent pas nécessairement une agriculture commerciale dans le sens plein du terme. L'exploitation agricole demeure fondamentalement la même. Le niveau de la production reste relativement bas et les techniques agricoles, qui ont un effet direct sur les rendements, sont à peine améliorées. En ce domaine, les progrès sont particulièrement lents. Dans le comté de Bellechasse et sur l'île d'Orléans, la production moyenne par ferme est plus considérable que sur la côte de Beaupré et que dans le comté de Saguenay: 139 et 152 minots par ferme contre 103 et 120. Dans Portneuf, cette moyenne est de 123. Dans les environs de Québec, la pomme de terre et l'avoine ont vraiment permis l'éclosion d'une agriculture de type commercial. Le blé ne représente que $5 \%$ de la moisson même si la majorité des cultivateurs canadiens-français maintient son attachement à cette culture. Ainsi, à Charlesbourg, la production moyenne par ferme atteint 170 minots pour la pomme de terre et 129 pour l'avoine. Le récolte détaillée des cinq plus importants agriculteurs du lieu illustre cette question des élites agricoles. 
P. Chalifour, cult., 200 arp., blé 80 , pois 14 , avoine 200 , patates 900 ;

E. Lefebvre, cult., 140 arp., blé, 59 , pois 10 , avoine 225 , patates 991 ;

J. Paradis, cult., 100 arp., blé 50 , avoine 100 , patates 700 ;

T. Bourke, fermier, 240 arp., blé 50 , pois 40 , avoine 700 , patates 5000 ;

J.-B. Jobin, cult., 590 arp., blé 211, pois 33 , avoine 580, patates 200.

Bien que tous ces cultivateurs aient des surplus appréciables de production, ils ne pratiquent pas tous une agriculture qui soit vraiment de type commercial. Seul Bourke, un des rares Anglophones du lieu, appartient à cette catégorie. A lui seul, il récolte $13 \%$ des pommes de terre de la paroisse. A l'Ancienne-Lorette et à St-Ambroise, localités presqu'exclusivement canadiennes-françaises, la production moyenne de pommes de terre est plus basse: 136 et 127 minots par ferme. Par contre, à Valcartier, colonie majoritairement anglophone, la moyenne est beaucoup plus élevée: 394 minots par ferme. A cet endroit, 14 cultivateurs, tous Anglophones, récoltent entre 1000 et 2000 minots de pommes de terre. Les onze cultivateurs canadiens-français recueillent entre 80 et 550 minots. Plus près de la ville, à Petite-Rivière St-Charles, les disparités sont encore plus marquées. Les différences ne sont pas que quantitatives.

$\begin{array}{lrc} & \text { avoine (minots) } & \text { pommes de terre (minots) } \\ \text { Canadiens français } & & 29 \\ \text { producteurs } & 24 & 6969 \\ \text { production } & 5161 & 240 \\ \text { production moyenne } & 215 & 19 \\ \text { Anglophones } & 18 & 18846 \\ \text { producteurs } & 6460 & 991 \\ \text { production } & 358 & \end{array}$

A Ste-Foy, les disparités sont également très nettes: 46 producteurs canadiens-français recueillent 18056 minots de pommes de terre pour une récolte moyenne de 392 minots; 30 Anglophones en recueillent 22658 minots pour une moyenne de 755 minots. Encore ici les écarts sont substantiels et ils permettent de saisir la nuance entre le cultivateur qui a des surplus négociables et l'exploitation commercialisée. Le cas de Beauport amène à pousser cette distinction plus loin. Le blé ne retient que $17 \%$ de la production totale de la paroisse. La pomme de terre et l'avoine sont la base de l'activité agricole. L'équilibre des groupes ethniques en ce qui concerne la pomme de terre est le suivant: 183 cultivateurs canadiens-français ont une production de 17338 minots et une production moyenne de 95 minots; 13 producteurs anglophones produisent 15360 minots pour une moyenne de 1181 minots. Dans l'ensemble, ces chiffres indiquent des écarts qui 
ressemblent à ceux observés dans la paroisse de Montréal. ${ }^{3}$ Ils montrent la différence entre une agriculture s'inspirant au point de départ de l'idée de subsistance et une agriculture où les intentions de profit sont plus fondamentales. Il est évident que tous les Anglophones n'appartiennent pas à l'élite agricole mais ils l'habitent en plus grand nombre. Dans la mesure où l'activité agricole s'est commercialisée, ils en sont les principaux artisans et bénéficiaires.

La question de l'élevage possède aussi ses complexités. Nombreux sont les artisans et les journaliers, pour ne pas dire commerçants, curés, professionnels et autres, qui récoltent quelques minots d'avoine et de pommes de terre; mais plus nombreux encore sont ceux qui entretiennent sur leurs terrains quelques animaux: bêtes à cornes, chevaux et porcs. Les éleveurs de bêtes à cornes et de porcs forment 82 et $80 \%$ des chefs de famille. Le reste des éleveurs, selon les besoins de la subsistance, les possibilités du marché, la dimension de la terre, l'existence de communaux et le dynamisme personnel, se répartit d'une façon fort inégale sur le territoire.

La dimension des troupeaux de bêtes à cornes dépend pour une part de l'étendue de la terre. De façon générale, les troupeaux importants se trouvent chez les gros propriétaires de terres. Ce qui ne signifie pas que tous les gros propriétaires fonciers soient propriétaires de gros troupeaux. D'ailleurs l'expansion de la décennie 1820-30 avait été considérable mais encore limitée. La proportion élevée de ceux qui gardent 5 bêtes à cornes et moins le prouve. Elle allait augmenter durant la décennie suivante avec la détérioration des conditions économiques et le morcellement accru de la terre.

La distinction entre ceux qui sont simplement à la recherche de la subsistance et ceux qui écoulent les produits laitiers et les viandes de boucherie sur le marché, n'est pas aisée à établir. Tout dépend du marché et des standards de qualité exigés. A l'instar du blé, le secteur de l'élevage fait l'objet d'une forte compétition extéricure. Peut-être la possession de 11 bêtes à cornes et plus serait-elle l'indication d'une attention aux besoins du marché? En ce sens, les comtés de Bellechasse, Lislet, la côte de Beaupré et l'île d'Orléans détiendraient une sorte de primauté. Remarquons ici que ces régions ne renferment pas de minorités anglophones significatives. Ce qui voudrait dire que celles-ci n'accordent pas une attention particulière à l'élevage. Les town-

${ }^{3} \mathrm{~F}$. Ouellet, Eléments d'histoire sociale du Bas-Canada, 177. 
ships du district de Québec, pas plus que les concentrations anglophones à l'intérieur des seigneuries, ne manifestent de prédilection particulière pour l'élevage. La situation est différente dans le district de Montréal.

\section{BÊTES À CORNES}

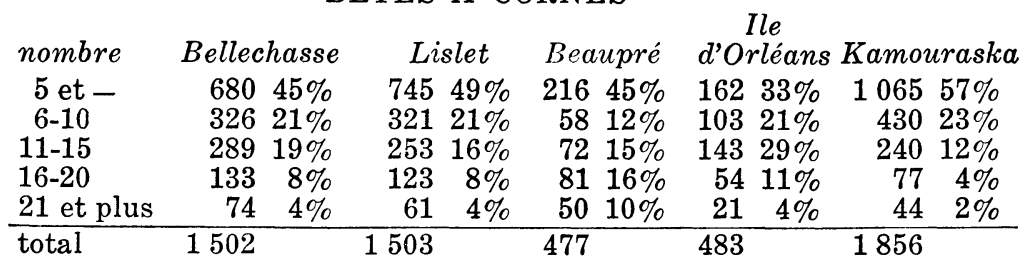

Il est évident que l'équilibre de la propriété foncière détermine les possibilités de développement de l'élevage des bêtes à cornes. A cet égard le contraste entre Lislet et Kamouraska est frappant. La proximité du marché est aussi un facteur d'expansion tout comme les conditions économiques générales.

\begin{tabular}{|c|c|c|c|c|c|c|c|c|c|c|}
\hline \multirow[b]{2}{*}{ nombre } & \multicolumn{9}{|c|}{ BÊTES À CORNES } & \multirow[b]{2}{*}{$\begin{array}{c}\text { Portneuf } \\
(18,+2)\end{array}$} \\
\hline & Lotb & inière & Dorc & hester & Sag & cenay & $\begin{array}{l}\text { Sag? } \\
1 \quad(18\end{array}$ & $\begin{array}{l}\text { ienay } \\
842)\end{array}$ & Portneuf & \\
\hline $\begin{array}{l}5 \text { et }- \\
6-10\end{array}$ & $\begin{array}{l}602 \\
288\end{array}$ & $\begin{array}{l}53 \% \\
25 \%\end{array}$ & $\begin{array}{l}612 \\
342\end{array}$ & $\begin{array}{l}50 \% \\
28 \%\end{array}$ & $\begin{array}{l}617 \\
340\end{array}$ & $\begin{array}{l}49 \% \\
27 \%\end{array}$ & $\begin{array}{l}358 \\
210\end{array}$ & $\begin{array}{l}49 \% \\
28 \%\end{array}$ & $\begin{array}{l}804 \\
470 \quad 28 \%\end{array}$ & $\begin{array}{ll}683 & 57 \% \\
328 & 27 \%\end{array}$ \\
\hline $11-$ & 173 & $15 \%$ & 175 & $14 \%$ & 179 & $14 \%$ & 119 & $16 \%$ & $28016 \%$ & $11916 \%$ \\
\hline $16-2$ & 47 & $4 \%$ & 58 & $4 \%$ & 83 & $6 \%$ & 29 & 3 ? & 7140 & $25 \quad 2 \%$ \\
\hline 1 et plus & 16 & $1 \%$ & 32 & $2 \%$ & 37 & $2 \%$ & 14 & $1 \%$ & $2 \%$ & $5-$ \\
\hline tal & 1126 & & 1219 & & 1256 & & 730 & & 1662 & 160 \\
\hline
\end{tabular}

Les chiffres pour 1842, incomplets pour le Saguenay, mettent l'accent sur le déclin qui se produit après 1831. Ceux de 1831 montrent le rapport entre la répartition de la terre, l'équilibre économique général et l'ampleur des troupeaux. Il est des régions où l'anémie généralisée est le principal facteur d'explication: c'est le cas de la Beauce et du comté de Rimouski. Dans les environs de Québec, le petit nombre de bêtes à cornes est essentiellement lié au morcellement de la terre.

\section{BÊTES À CORNES}

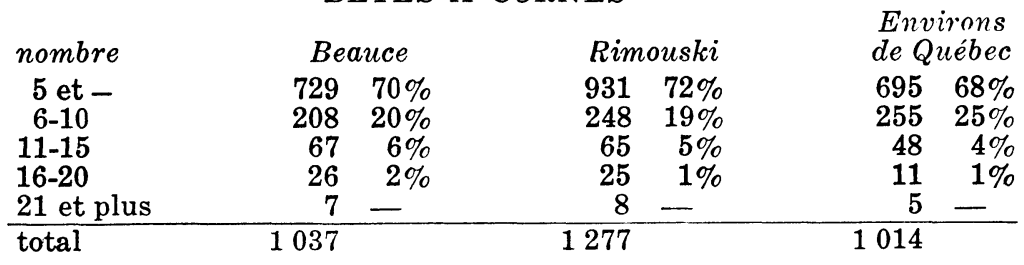


L'élevage du porc ne dépend pas au même degré de l'étendue de la terre ou de l'existence des communaux. Mais lui aussi concerne directement les changements dans l'alimentation et le marché local ou urbain. L'expansion durant les années 1820-30 prend vite fin à partir de 1831 avec la multiplication des mauvaises récoltes et la généralisation de la crise. Si la catégorie des propriétaires de 5 porcs et moins recouvre assez bien l'intention d'auto-suffisance, les autres catégories reflètent les ventes. Le bœuf de boucherie et le porc ont preneurs dans les campagnes, sur le marché urbain, dans les exploitations forestières et dans les pêcheries. Le classement des régions selon ce critère permet de saisir les contrastes du territoire.

\begin{tabular}{|c|c|c|c|c|c|}
\hline \multirow[b]{2}{*}{ nombre } & \multicolumn{4}{|c|}{ PORCS } & Saguen:y \\
\hline & Bellechasse & Lislet & Kamouraska & Saguenay & $(1842)$ \\
\hline $\begin{array}{l}5 \text { et - } \\
6-10\end{array}$ & $\begin{array}{l}73651 \% \\
493 \quad 34 \%\end{array}$ & $\begin{array}{ll}760 & 50 \% \\
583 & 38 \%\end{array}$ & $\begin{array}{r}104057 \% \\
51128 \%\end{array}$ & $\begin{array}{ll}495 & 40 \% \\
513 & 41 \%\end{array}$ & $\begin{array}{rl}557 & 82 \% \\
99 & 14 \%\end{array}$ \\
\hline $11-15$ & $16211 \%$ & $1519 \%$ & $19110 \%$ & $18615 \%$ & $223 \%$ \\
\hline $16-20$ & $27 \quad 1 \%$ & $20 \quad 1 \%$ & $50 \quad 2 \%$ & $28 \quad 2 \%$ & $1-$ \\
\hline 21 et plus & $6-$ & $3-$ & $13-$ & $4-$ & $0-$ \\
\hline total & 1424 & 1517 & 1805 & 1226 & 679 \\
\hline
\end{tabular}

Dans les autres régions, le groupe de ceux qui gardent onze porcs et plus est de plus en plus réduit: en gros il passe de 12 à $6 \%$.

\begin{tabular}{|c|c|c|c|c|c|}
\hline nombre & Lotbinière & Dorchester & Rimouski & Beaupré & $\begin{array}{c}\text { Ilé } \\
\text { d'Orléans }\end{array}$ \\
\hline $\begin{array}{l}5 \text { et - } \\
6-10\end{array}$ & $\begin{array}{l}79669 \% \\
280 \\
24 \%\end{array}$ & $\begin{array}{l}80367 \% \\
31926 \%\end{array}$ & $\begin{array}{l}83466 \% \\
32926 \%\end{array}$ & $\begin{array}{l}20449 \% \\
18745 \%\end{array}$ & $\begin{array}{l}30366 \% \\
13128 \%\end{array}$ \\
\hline $11-15$ & $58 \quad 5 \%$ & $605 \%$ & $86 \quad 6 \%$ & $204 \%$ & $224 \%$ \\
\hline $16-20$ & $9-$ & $131 \%$ & $4-$ & $3-$ & $2-$ \\
\hline 21 et plus & $3-$ & $3-$ & $4-$ & $1-$ & $0-$ \\
\hline total & 1146 & 1198 & 1257 & 415 & 458 \\
\hline
\end{tabular}

Ailleurs les détenteurs de surplus sont encore moins nombreux. Dans la Beauce, les performances sont minimales en termes de subsistance.

\begin{tabular}{|c|c|c|c|c|c|c|c|c|}
\hline \multirow{2}{*}{$\begin{array}{c}\text { nombre } \\
5 \text { et - } \\
6-10\end{array}$} & \multicolumn{2}{|c|}{ Beauce } & \multicolumn{2}{|c|}{$\begin{array}{l}\text { Env.de } \\
\text { Québec }\end{array}$} & \multicolumn{2}{|c|}{ Portneuf } & \multicolumn{2}{|c|}{$\begin{array}{c}\text { Portneuf } \\
(1842)\end{array}$} \\
\hline & $\begin{array}{l}857 \\
127\end{array}$ & $\begin{array}{l}85 \% \\
12 \%\end{array}$ & $\begin{array}{l}649 \\
199\end{array}$ & $\begin{array}{l}74 \% \\
22 \%\end{array}$ & $\begin{array}{r}1024 \\
580\end{array}$ & $\begin{array}{l}62 \% \\
35 \%\end{array}$ & $\begin{array}{r}1074 \\
70\end{array}$ & $\begin{array}{r}93 \% \\
6 \%\end{array}$ \\
\hline $11-15$ & 11 & $1 \%$ & 18 & $2 \%$ & 42 & $2 \%$ & 2 & \\
\hline $16-20$ & 1 & - & 3 & - & 2 & - & 0 & - \\
\hline 21 et plus & 1 & - & 0 & - & 2 & - & 0 & - \\
\hline total & 997 & & 869 & & 1650 & & 1146 & \\
\hline
\end{tabular}


Le recensement de 1831, établi en année de bonne récolte, fait à la fois saisir les mutations de l'agriculture bas-canadienne en cette première moitié du XIXe siècle et soulève le problème des disparités régionales et locales. A cette date, le phénomène n'est pas achevé de sorte que la situation peut sembler anarchique, car les différences d'une localité à l'autre et d'une région à l'autre ne paraissent pas être le seul fruit de vocations bien établies en fonction de la nature des sols et des réalités économiques. Partout les équilibres existants sont précaires et le contexte mouvant. En 1842, la transition est opérée mettant en évidence une structure de la production plus uniforme, mais centrée sur la pomme de terre et parfois sur l'avoine. Le blé est vraiment devenu une production secondaire à laquelle le paysan a été forcé de renoncer. Mais, en 1831, le phénomène du recul de la culture du blé est déjà très avancé de sorte que le froment ne domine la récolte qu'en certains endroits. Le recensement de 1831 pose aussi le problème des écarts régionaux. La distinction entre une agriculture de subsistance, tantôt déficitaire et tantôt excédentaire, et une agriculture commercialisée, semble un concept utile lorsqu'il s'agit d'évaluer la situation.

Les comtés de Lislet et de Kamouraska avaient conservé en 1831 un type d'agriculture solidement axé sur le blé. Là aussi la production de la pomme de terre avait fait des progrès remarquables depuis le début du siècle. Mais la richesse du sol ou une répartition avantageuse de la propriété ont permis de maintenir la suprématie du blé et font de cette région une des plus productives, quantitativement parlant, du district de Québec, peut-être du Bas-Canada. D'une paroisse à l'autre, l'inégalité des performances est frappante, mais l'impression d'ensemble est rassurante. Apparemment le système semble bien fonctionner. Mais un coup d'œil sur les rendements et sur le morcellement de la terre dans Kamouraska suggère une appréciation moins optimiste de la situation.

PRODUCTION MOYENNE PAR FERME

\begin{tabular}{|c|c|c|c|c|c|}
\hline & blé & avoine & $\begin{array}{l}\text { pommes } \\
\text { ce terre }\end{array}$ & $\begin{array}{l}\text { bêtes à } \\
\text { cornes }\end{array}$ & porcs \\
\hline St-Roch-des-Aulnaies & 198 & 96 & 118 & 8.1 & 6.3 \\
\hline Lislet & 192 & 64 & 73 & 6.6 & 5.4 \\
\hline Cap St-Ignace & 108 & 42 & 86 & 6.6 & 5.4 \\
\hline St-André & 67 & 39 & 75 & 5.5 & 4.8 \\
\hline St-Louis & 175 & 151 & 92 & 7.9 & 7.6 \\
\hline St-Pascal & 112 & 25 & 76 & 5.4 & 5.7 \\
\hline Rivière-Ouelle & 151 & 108 & 75 & 5.3 & 5.7 \\
\hline
\end{tabular}


Dans plusieurs de ces paroisses, les minorités de producteurs de blé excédentaires sont énormes: les producteurs de plus de 200 minots atteignent 38\% à St-Roch, 30\% à Lislet, 31\% à St-Louis et $26 \%$ à Rivière-Ouelle. Ceux-ci sont souvent de gros producteurs d'avoine ou de pommes de terre: à St-Louis, $25 \%$ des producteurs d'avoine récoltent plus de 200 minots; à St-Roch et à Lislet, $15 \%$ des producteurs recueillent plus de 200 minots de pommes de terre. Il existe donc un noyau de paroisses où une élite agricole nombreuse dispose d'excédents considérables de blé et autres denrées. Les perspectives de commercialisation de l'agriculture par le blé semblent à première vue très bonnes. Mais le morcellement de la terre, en particulier dans Kamouraska, l'épuisement des sols et la mouche à blé auront vite raison de ce système. En 1842, l'avoine et la pomme de terre constituent 96 et $97 \%$ de la moisson. Cette région semble pratiquer une agriculture de subsistance fortement excédentaire en période de bonne récolte. Mais les cultivateurs, depuis les déficitaires jusqu'aux excédentaires, ne représentent que $60 \%$ des chefs de famille. On peut croire que les surplus sont presque entièrement écoulés sur le marché régional.

Le comté de Bellechasse possède aussi une élite agricole dont l'activité est centrée sur la production de l'avoine, de la pomme de terre et sur l'élevage. A St-Michel et à St-Charles, 18 et $14 \%$ des producteurs d'avoine récoltent plus de 200 minots; dans les mêmes paroisses et dans Beaumont, 21,31 et $26 \%$ des producteurs de pommes de terre appartiennent à la même catégorie. L'élevage y est pratiqué sur une plus grande échelle qu'ailleurs.

\begin{tabular}{|c|c|c|c|c|c|}
\hline & $\begin{array}{l}\text { MO } \\
\text { blé }\end{array}$ & avoine & pommes & $\begin{array}{c}\text { bêtes à } \\
\text { cornes }\end{array}$ & porcs \\
\hline $\begin{array}{l}\text { St-Vallier } \\
\text { St-Gervais } \\
\text { Beaumont } \\
\text { St-Michel } \\
\text { St-Charles }\end{array}$ & $\begin{array}{r}75 \\
50 \\
73 \\
100 \\
76\end{array}$ & $\begin{array}{r}103 \\
72 \\
124 \\
141 \\
125\end{array}$ & $\begin{array}{l}120 \\
109 \\
157 \\
156 \\
191\end{array}$ & $\begin{array}{l}9.1 \\
6.6 \\
6.7 \\
8.6 \\
9.4\end{array}$ & $\begin{array}{l}5.3 \\
4.7 \\
5.2 \\
8.2 \\
7.2\end{array}$ \\
\hline
\end{tabular}

Dans ces paroisses, l'élite agricole semble à la fois plus réduite et plus articulée au marché urbain. L'adaptation au déclin accéléré du froment en sera peut-être facilitée.

\begin{tabular}{|c|c|c|c|c|c|}
\hline \multicolumn{6}{|c|}{ PRODUCTION MO } \\
\hline & blé & avoine & $\begin{array}{l}\text { pommes } \\
\text { de terre }\end{array}$ & $\begin{array}{l}\text { bêtes à } \\
\text { cornes }\end{array}$ & porcs \\
\hline $\begin{array}{l}\text { Saguenay } \\
\text { Beaupré }\end{array}$ & $\begin{array}{l}116 \\
118\end{array}$ & $\begin{array}{r}38 \\
116\end{array}$ & $\begin{array}{l}120 \\
103\end{array}$ & $\begin{array}{l}7.8 \\
9.2\end{array}$ & $\begin{array}{l}6.8 \\
5.5\end{array}$ \\
\hline Ile d'Orléans & 99 & 120 & 152 & 8.9 & 4.7 \\
\hline
\end{tabular}


La région qui comprend le comté de Saguenay, la côte de Beaupré et l'île d'Orléans, présente certaines particularités. La production du blé, excepté au Saguenay, y est plus qu'ailleurs concentrée entre les mains d'un groupe restreint et celle de la pomme de terre est largement répartie entre une masse de petits et de moyens producteurs. L'ensemble de la production est donc dominée par la pomme de terre, mais le rendement moyen par ferme produisant du froment indique la forte position du blé parmi les gros propriétaires fonciers. Partout le morcellement de la terre comporte l'abandon du blé et son remplacement par la pomme de terre; mais, à l'île d'Orléans et sur la côte de Beaupré, cette tendance est encore plus évidente. Le regroupement de la propriété foncière et les efforts pour mettre obstacle à la fragmentation des patrimoines n'ont pas donné naissance à une élite agricole aussi nombreuse que dans Lislet et Kamouraska. Pourtant la proximité du marché urbain et les pêcheries favorisent plus généralement cette région. C'est pourquoi l'élevage y est-il plus largement pratiqué que dans Lislet et Kamouraska. Le déclin du blé après 1831 aura là aussi l'aspect d'un phénomène très brutal.

Dans les environs de Québec, la commercialisation de l'agriculture par l'avoine et la pomme de terre s'opère autour d'un petit nombre de gros producteurs se recrutant surtout dans le milieu anglophone. Ici le fermier, locataire de terre, a davantage d'importance que le cultivateur propriétaire. Les disparités sont extraordinaires: la paroisse de Beauport fournit le meilleur exemple des écarts qui existent entre l'agriculture de subsistance déficitaire et l'agriculture commercialisée. La structure de la production dans cette région au sol morcelé ressemble à celle qui prévaut dans les cantons ou dans les localités seigneuriales à forte présence anglophone.

\section{PRODUCTION MOYENNE PAR FERME}

$\begin{array}{lccccc} & \text { blé } & \text { avoine } & \begin{array}{c}\text { pommes } \\ \text { de terre }\end{array} & \begin{array}{c}\text { bêtes } \\ \text { cornes }\end{array} & \text { porcs } \\ \text { Leeds (township) } & 65 & 32 & 392 & 7.7 & 8.3 \\ \text { Petite-Rivière St-Charles } & 29 & 281 & 508 & 5.1 & 4.7 \\ \text { Ste-Foy } & 39 & 124 & 449 & 6.7 & 4.5 \\ \text { Beauport } & 57 & 70 & 161 & 4.0 & 3.2 \\ \text { Charlesbourg } & 36 & 129 & 170 & 3.9 & 5.9 \\ \text { Ste-Catherine (Portneuf) } & 18 & 80 & 267 & 3.5 & 4.9\end{array}$

Le reste du district de Québec paraît plus ou moins voué à la médiocrité. Dans la Beauce, la crise est profonde. Dans Rimous- 
ki, Lotbinière, Dorchester et Portneuf, la situation est moins sérieuse, mais les performances sont encore médiocres si on les compare à celles des régions avantagées. L'élite agricole, bien qu'elle existe, est numériquement faible et manque de vigueur.

\section{PRODUCTION PAR FERME}

\begin{tabular}{|c|c|c|c|c|c|}
\hline & blé & avoine & $\begin{array}{l}\text { pommes } \\
\text { de terre }\end{array}$ & $\begin{array}{l}\text { bêtes à } \\
\text { cornes }\end{array}$ & porcs \\
\hline Ste-Marie (Beauce) & 40 & 32 & 83 & 5.2 & 3.3 \\
\hline Ste-Claire & 24 & 27 & 68 & 2.8 & 2.7 \\
\hline St-Antoine (Lotbinière) & 60 & $\overline{7} 7$ & 98 & 7.5 & 3.9 \\
\hline Ste-Croix & 63 & 63 & 97 & 6.8 & 3.7 \\
\hline St-Louis & 83 & 89 & 99 & 7.7 & 6.5 \\
\hline St-Joseph (Dorchester) & 35 & 74 & 82 & 4.4 & 3.3 \\
\hline St-Jean & 48 & 71 & 74 & 5.6 & 4.3 \\
\hline St-Nicolas & 66 & 77 & 118 & 7.7 & 5.2 \\
\hline St-Henri & 51 & 70 & 92 & 6.9 & 5.1 \\
\hline Cap-Santé (Portneuf) & 58 & 113 & 99 & 6.8 & 4.5 \\
\hline
\end{tabular}

Dans la plupart de ces paroisses, l'activité agricole est dominée par le paysan déficitaire, qui est d'ailleurs en grand nombre sur tout le territoire. Partout aussi, à part une concentration dans les environs de Québec, il existe des individus isolés pratiquant à tous égards une agriculture de type commercial. A ce point de vue, la prédominance des Anglophones est manifeste. Entre le paysan déficitaire et l'agriculteur commercialisé, il y a le cultivateur excédentaire. On peut affirmer avec certitude que tous ceux qui produisent moins de 50 minots appartiennent à la catégorie des déficitaires. Les pourcentages sont $50 \%$ pour les producteurs de blé, $52 \%$ pour les producteurs d'avoine et $39 \%$ pour les producteurs de pommes de terre. Signalons à nouveau que les producteurs de blé ne constituent que $59 \%$ des chefs de famille et les cultivateurs $67 \%$. Du point de vue de l'élevage, on observe le même phénomène: $54 \%$ des éleveurs de bêtes à cornes en possèdent 5 et moins; $60 \%$ des éleveurs de porcs en engraissent 5 et moins. Par contre le groupe de ceux qui produisent plus de 200 minots est fort réduit: $6 \%$ pour le blé, $6 \%$ pour l'avoine et $11 \%$ pour la pomme de terre. Les éleveurs de 21 bêtes à cornes et plus sont de $2 \%$ et ceux qui gardent plus de 10 porcs s'évaluent à $8 \%$ des éleveurs de porcs. Tout cela illustre bien les inégalités qui existent entre les différentes catégories de producteurs. Heureusement le district de Québec ne vivait pas que de l'agriculture: la construction navale, l'exploitation forestière et les pêcheries, en plus de servir à étendre le marché agricole, étaient génératrices d'emplois. 


\section{CONCLUSION}

La statistique sur laquelle se fonde cette analyse, recouvre plus de 20000 chefs de tamille et regroupe un minimum de 130000 données tirées principalement du recensement nominatif de 1831 et, très secondairement, de celui de 1842. Cette floraison d'informations permet d'apercevoir le détail du paysage agraire et rural. Ce défilé de familles et d'exploitations agricoles, paroisse par paroisse, produit un tableau tout en nuances. Mais les contrastes et les différences de toutes sortes, tant au plan des occupations qu'au niveau de la répartition de la terre et de l'exploitation du sol, ne masquent pas entièrement les traits essentiels du paysage humain. Même si le paysan propriétaire domine numériquement la vie locale, le curé, le seigneur, le professionnel, le marchand, l'instituteur, l'artisan et le journalier sont solidement enracinés dans le milieu. Il est même des endroits où le paysan ne fait pas la moitié des effectifs. Il est vrai que certaines paroisses font encore songer à une époque où la structure des occupations était simplifiée au maximum; mais, dans l'ensemble, cette période est révolue pour les localités bien établies. La société rurale possède maintenant ses complexités. Certains groupes occupationnels sont même encombrés. Le journalier n'est pas le seul candidat éventuel à l'émigration. Bien des paysans, des fils de cultivateurs ou d'artisans se situent dans cette catégorie. Car la rareté des terres et la forte natalité forcent les jeunes, parfois les moins jeunes, à partir. Cette population serait donc instable à nombre de points de vue. Ce monde rural, du point de vue ethnique et religieux, n'est pas uniforme. Le Canadien français le domine sans doute numériquement, mais des Anglophones, protestants ou catholiques, sont présents et inscrivent dans le milieu des inégalités qui sont ou seront parfois plus fortement ressenties que les disparités sociales traditionnelles.

D'autre part nombre d'idéaux du passé sont devenus difficiles à réaliser. Ainsi l'accès à la propriété foncière n'est plus une chose qui va de soi. De nombreux fils de cultivateurs, d'artisans et de journaliers ne peuvent réaliser leur rêve sans quitter la paroisse et l'entourage familial. Les locataires sont d'ailleurs nombreux dans les campagnes: $18 \%$ des chefs de famille. La situation est pourtant meilleure à cet égard que dans le district de Montréal où environ $25 \%$ des chefs de famille ruraux sont locataires. De même le paysan, possesseur de ses 90 arpents, est un autre rêve du passé: $45 \%$ des terres ont 50 arpents et moins. L'épuisement des sols fait peu à peu tomber la productivité de ces terres et de celles qui sont plus étendues. Le morcellement de la propriété foncière est donc une réalité contraignante 
qui, en l'absence de renouvellement des pratiques agricoles, affecte considérablement la vie paysanne. Même si les sols sont généralement moins riches que dans la région de Montréal, l'exploitant rural y possède davantage de terre. Le destin de cette masse de petits propriétaires et de locataires contraste singulièrement avec celui des minorités qui, directement ou indirectement, contrôlent le terroir. Bien sûr les seigneurs constituent une catégorie à part. Tout le territoire en bordure du fleuve étant divisé en seigneuries, les seigneurs se trouvent par le fait même à exercer une emprise sur les censitaires qui payent la rente. Certaines seigneuries, telle Beaupré appartenant au Séminaire de Québec, sont énormes et le seigneur en tire des revenus considérables. Par contre de nombreuses seigneuries sont possédées par plus d'une dizaine de seigneurs qui perçoivent des droits sur des portions de fiefs. La fragmentation de la propriété seigneuriale fait de cette classe un groupe très divers. Les domaines, propriété directe des seigneurs, sont aussi fort inégaux quant à l'étendue qui varie entre 200 et 1400 arpents. Il se trouve aussi des marchands, des bourgeois, des professionnels, voire des artisans, des curés et des instituteurs, qui figurent parmi les grands propriétaires. Mais, d'une façon générale, la propriété foncière reste dans les mains de la paysannerie.

La majorité des gros propriétaires fonciers est formée de cultivateurs intéressés à spéculer ou à simplement concentrer la terre entre leurs mains. Cette minorité peut être estimée à $7 \%$ et comprend ceux qui possèdent plus de 200 arpents de terre. Certains d'entre eux ont même 1000 arpents et davantage. Les motivations des éléments qui ont résisté au mouvement vers le morcellement de la terre et qui sont parvenus à étendre leur domaine, ne sont pas aisées à déterminer. Il est certain cependant qu'une forte proportion (24\%) de ceux qui ont plus de 100 arpents de terre, était consciente des dangers que représentait la tendance au morcellement inscrite dans le droit successoral. L'émiettem $€$ nt de la propriété foncière mettait en cause la stabilité économique des familles. Par contre le maintien des patrimoines ou leur accroissement obligeaient les jeunes à émigrer ou à entrer dans la masse des journaliers. Il est évident que la paysannerie était alors aux prises avec ces problèmes. A bien des endroits, de fortes minorités paysannes avaient opté pour la préservation des patrimoines. Ces paroisses sont des pourvoyeuses d'émigrants que les villes ne peuvent absorber. La recherche des terres les conduit peu à peu vers le district de Montréal. En 1931, le phénomène est engagé depuis longtemps.

Le rêve d'une agriculture principalement centrée comme autrefois sur le blé, bien que toujours vivace en 1831, est en 
voie de perdre ses appuis dans la réalité. A cette date, le cultivateur n'est pas nécessairement un producteur de blé. Le nombre des producteurs de froment décroît sans cesse. L'épuisement des sols, la pauvreté des techniques et le morcellement de la terre expliquent ces abandons. Ils rendent compte aussi de la multiplication rapide des petits producteurs, en particulier de ceux qui récoltent 50 minots et moins. Quelques années encore et ils auront abandonné cette culture. Il est pourtant des endroits où l'agriculture se rapproche de ce qu'elle était au $X V I I I^{e}$ siècle. Le sol y est plus riche qu'ailleurs et l'équilibre de la propriété foncière penche en faveur des gros possédants qui, néanmoins, sont en train de perdre contact avec le marché international. Dans Kamouraska, la survie du blé est surtout liée à la nature des sols qui favorise aussi les paroisses du comté de Lislet où la concentration des terres est un phénomène remarquable. Sur l'île d'Orléans et davantage sur la côte de Beaupré, la résistance de la culture du froment exprime le maintien ou la constitution plus ou moins récente d'unités de production plus vastes. A ces derniers endroits, comme dans le comté de Saguenay, la pomme de terre a déjà supplanté le blé dans la récolte. Partout ailleurs ce type de cultivateur traditionnel régresse au profit du producteur de pommes de terre et d'avoine. En 1842, il aura presque complètement disparu tout en conservant la nostalgie des formules anciennes. Vers 1850, il tend à renaître localement, ce qui n'empêche pas la déchéance de se poursuivre.

L'agriculteur de 1831 porte maintenant une attention particulière à la culture de la pomme de terre. Même dans Lislet et Kamouraska, cette culture a fait des progrès étonnants et le nombre de producteurs de pommes de terre surclasse faiblement celui des producteurs de froment. Dans le reste du district cet écart s'élargit.

$\begin{array}{lcc} & \begin{array}{c}\text { producteurs } \\ \text { de pommes de terre }\end{array} & \begin{array}{c}\text { producteurs } \\ \text { de blé }\end{array} \\ \text { Dorchester } & 1189 & 938 \\ \text { Lotbinière } & 1162 & 965 \\ \text { Beauce } & 989 & 910 \\ \text { Saguenay } & 1025 & 946 \\ \text { Beaupré } & 475 & 334 \\ \text { Ile d'Orléans } & 424 & 424 \\ \text { Env. de Québec } & 1136 & 463 \\ \text { Portneuf } & 1583 & 1092\end{array}$

Le producteur de pommes de terre est d'abord né de l'épuisement des sols et de l'émiettement de la propriété foncière. Le petit propriétaire cultive presque nécessairement la "patate". Il est cependant des cultivateurs, dont le nombre croît rapide- 
ment, qui non seulement considèrent la pomme de terre comme une production importante, mais qui lui accordent un rôle prédominant dans la récolte. Ces cultivateurs, possesseurs de terres de toutes dimensions, ne sont encore que des minorités importantes sur la plus grande partie du territoire. Par contre, ils sont l'immense majorité dans certaines régions. Dans les cantons et les paroisses, peuplés d'Anglophones, l'agriculteur est avant tout un producteur de pommes de terre. Partout où les Anglophones sont établis, ce type de cultivateur se multiplie, même chez les Canadiens français pourtant si attachés au blé. Dans les environs de Québec, la pomme de terre sert de fondement à toute l'activité agricole: agriculture de subsistance et agriculture commercialisée. Les Anglophones sont les initiateurs et les principaux bénéficiaires de cette agriculture transformée.

Partout le cultivateur doit produire pour alimenter sa famille, effectuer les semences, payer la dîme au curé et la rente au seigneur, contribuer aux frais du culte. Dans cette perspective, l'activité agricole appelle la constitution d'un surplus destiné au marché. Mais le surplus n'est pas obtenu chaque année par le même nombre de producteurs. La proportion des paysans excédentaires et déficitaires varie selon le jeu des bonnes et des mauvaises récoltes. Il est aussi fonction de la place qu'occupe le paysan dans la structure agraire. Le pourcentage des producteurs excédentaires en 1831, après la bonne récolte de 1830 , ne dépasse pas $20 \%$ ou $22 \%$ de la paysannerie. Le marché local ou régional est donc devenu important. Mais le cultivateur doit aussi ravitailler la ville, les centres d'activité forestière et les pêcheries. Il existe également un important marché extérieur pour le blé. Cette minorité de producteurs excédentaires se répartit inégalement sur le territoire. Dans la Beauce, elle est inexistante. Ailleurs elle varie en fonction des besoins locaux et de ceux de la ville où elle subit la compétition extérieure. Sur la côte de Beaupré, sur l'île d'Orléans et dans les environs de Québec, comme dans Lislet, Kamouraska et Bellechasse, sa présence est plus manifeste. Mais, dans l'ensemble, cette minorité tend à perdre contact avec le marché international du blé et peut-être avec le marché urbain. Elle produirait surtout pour le marché local. Seule une petite élite maintient des rapports avec les marchés importants. Cette tendance allait s'accentuer pendant la décennie 1830-40 sous l'effet des conditions économiques et de la transformation structurelle. Le revenu paysan est en déclin.

Cette enquête sur le district de Québec en 1831 soulève une série de problèmes mettant en cause un large éventail de facteurs 
dont certains jouent depuis le début du XVIII ${ }^{\text {e }}$ siècle. Ainsi le caractère largement rural de cette société, qui le devient de plus en plus, est le produit d'une évolution amorcée dès le début du $\mathrm{XVIII}^{\mathrm{e}}$ siècle. Ce phénomène avait sa source principale dans l'incapacité des activités non-agricoles d'absorber les nouveaux éléments d'une population dont le rythme de croissance demeure toujours très rapide. L'abondance des terres facilite cette orientation rurale que seule l'industrialisation pourra finalement briser. Au XVIII' siècle, le trafic des pelleteries, les pêcheries et l'ouverture d'un marché extérieur pour le blé stimulent sans doute la croissance démographique, mais ne sont pas des facteurs bien puissants d'urbanisation. Le poids des campagnes augmente sans cesse. La substitution au début du XIX $\mathrm{X}^{\mathrm{e}}$ siècle du commerce du bois aux fourrures et l'apparition d'une rareté croissante, réelle ou artificielle, de terres dans la zone seigneuriale n'entravent pas ce processus. Les villes absorbent une certaine proportion des immigrants, mais les surcroits de population des campagnes cherchent une solution à leurs problèmes dans les milieux ruraux ou ils émigrent aux Etats-Unis. Même les villes semblent à certains moments une des sources de l'émigration canadienne-française. C'est certainement le cas de Montréal après 1825 ; c'est aussi celui de Québec entre 1825 et 1831 . Par la suite, si l'immigrant anglophone a tendance à quitter le Québec, il n'est pas nécessairement remplacé par le rural canadien-français. Cette ruralisation de la société est un phénomène dont les implications économiques, sociales et autres sont énormes. Il est certain qu'il n'incite pas en particulier à une élévation progressive du niveau d'instruction de la masse. Ce milieu suscite davantage l'analphabétisme.

La Nouvelle-France ne semble pas avoir connu ce que les historiens démographes appellent l'ancien régime démographique qui, en France, prend généralement fin vers 1750 . Au contraire les études de Henripin montrent, pour la première partie du XVIII ${ }^{e}$ siècle, une natalité exceptionnellement élevée et une faible mortalité. La rareté des hommes, l'abondance des terres et leur étendue, peut-être même le climat, sont des facteurs qui stimulent une forte croissance démographique. Dès lors la population canadienne-francaise double ses effectifs tous les vingt-cinq ou vingt-huit ans. Aussi longtemps que les terres sont abondantes, que le secteur agricole se développe sous l'impulsion d'un marché et que les autres conditions économiques sont propices, l'expansion de la population se fait librement. Elle maintiendra son rythme, puisque cette structure dépend aussi des valeurs de la société, même après le début du XIX ${ }^{e}$ siècle alors que les conditions changeront. La parcimonie de beaucoup de seigneurs en matière 
de concessions de terres, la rareté réelle de terres dans un nombre croissant de seigneuries et les mutations dans le secteur agricole créent une pression démographique qui gagne peu à peu l'étendue du territoire. Si les conditions de la croissance démographique étaient partout identiques, le peuplement se ferait au même rythme en tous lieux. Mais les circonstances sont variables d'un point à l'autre d'un territoire.

Le cas de l'île d'Orléans et des paroisses voisines de Québec est intéressant à cet égard. L'île est fertile, mais limitée par la géographie. L'augmentation de la population peut être qualifiée de lente. Si les cinq paroisses qui la composent avaient absorbé toute la croissance naturelle, non seulement elles auraient été surpeuplées en 1831, mais le sol aurait été morcelé à l'extrême. L'île aurait connu au XVIII siècle une crise économique et démographique profonde. Cette situation a pu être évitée parce que la paysannerie s'est préoccupée de maintenir une répartition équilibrée de la terre, créant ainsi un mouvement d'émigration vers des paroisses où des terres étaient disponibles. Dans les paroisses autour de la ville de Québec, la question démographique se pose aussi très tôt. La subdivision de la propriété foncière n'empêche cependant pas l'émigration de se produire; elle ne fait que retarder le moment du départ.

\section{ACCROISSEMENT DE LA POPULATION}

$\begin{array}{lrr} & 1765-1822 & 1822-1842 \\ \text { Ile d'Orléans } & 76 \% & 3 \% \\ \text { Charlesbourg } & 15 \% \text { (en 1825) } & 29 \% \text { (de 1825) } \\ \text { Beauport } & 75 \% & 32 \% \\ \text { Ancienne-Lorette } & 21 \% & 52 \% \\ \text { St-Augustin } & 160 \% & -21 \% \\ \text { Ecureuils } & 52 \% & \mathbf{9 \%}\end{array}$

Dans toutes ces paroisses situées près de Québec, l'accroissement naturel de la population entre 1794 et 1822 surpasse de beaucoup la différence entre les chiffres des recensements de 1784 et de 1822. Aux Ecureuils, par exemple, cet accroissement naturel est de 201 tandis que la population passe de 473 en 1784 à 462 en 1822.

Une comparaison entre la côte de Beaupré et deux paroisses du comté de Saguenay, les Eboulements et Baie-St-Paul, est significative des contrastes du territoire. La côte de Beaupré est un lieu de concentration des terres et d'émigration constante; le comté de Saguenay reçoit d'abord des immigrants pour devenir ensuite saturé. Vers 1825, la pression démographique apparaît et aboutit après 1830 à l'émigration. 


\section{ACCROISSEMENT DE LA POPULATION}

$\begin{array}{lcc} & 1765-1825 & 1825-1842 \\ \text { Beaupré } & 87 \% & 16 \% \\ \text { Saguenay } & 484 \% & 23 \%\end{array}$

Les cas d'explosion démographique ne sont pas rares pendant la période 1784-1810. Ces paroisses qui, en plus d'absorber la croissance naturelle, reçoivent des immigrants en nombre plus ou moins considérable, sont en général favorablement situées du point de vue qualité du sol, abondance des terres, et, parfois exploitation forestière. L'exemple le plus frappant est celui de St-Gervais dont la population passe de 683 habitants en 1784 à 5269 en 1822. Mais presque toujours, cette brutale poussée démographique est suivie après 1820 d'un recul des effectifs.

\section{ACCROISSEMENT DE LA POPULATION}

$\begin{array}{lrc} & 1765-1822 & 1822-1842 \\ \text { Ste-Marie de Beauce } & 972 \% & -18 \% \\ \text { St-Gervais } & 671 \% & (1784-1825) \\ \text { St-Joseph de Pte-Lévy } & 352 \% & -34 \% \\ \text { St-Henri } & 1013 \% & -16 \% \\ \text { St-Louis et Ste-Croix } & 321 \% & -22 \% \\ \text { Lislet } & 306 \% & 58 \% \\ \text { Kamouraska } & 284 \% & 32 \% \\ & & 11 \%\end{array}$

Les paroisses de Kamouraska, Rivière-Ouelle et Ste-Anne-de-laPocatière, ont en fait connu leur expansion majeure entre 1784 et $1822: 390 \%$. Mais ces localités sont loin d'avoir absorbé toute leur croissance naturelle. Entre 1765 et 1784, la population y décline de $21 \%$ tandis que l'augmentation de la population entre 1784 et 1822 est inférieure à l'accroissement naturel. Dans quatre paroisses importantes du comté de Lislet, même si la croissance se fait plus également après 1765 , le même écart existe entre la croissance naturelle et celle de la population pendant la période 1784-1822. Si par la suite la population continue de monter plus rapidement que dans Kamouraska, il faut sans doute l'attribuer à un meilleur équilibre dans la répartition de la propriété foncière. A Cap-Santé et aux Grondines, où la croissance est modérée entre 1765 et 1822 , l'augmentation rapide de la population entre 1822 et 1842 correspond à une phase de fragmentation de la propriété et, peut-être comme dans Lotbinière, à une attitude plus libérale de la part des seigneurs en matière de concession de terres.

Ces croissances inégales reflètent les étapes de la mise en valeur du terroir et du développement économique. Elles dépen- 
dent aussi de la politique des seigneurs, des pratiques sucessorales et, plus généralement, de l'attitude de la paysannerie à l'égard du remembrement ou du morcellement de la terre. La pression démographique qui se traduit par l'émigration ou par la constitution de groupes de journaliers, dont le sort est aussi de partir, devient un des principaux moteurs de la situation. Dans les paroisses où la concentration des terres était une réalité dominante, l'émigration est liée à l'attitude d'une minorité paysanne qui espère assurer sa survie économique. En fait la concentration des terres, sans une amélioration des techniques agricoles, ne pouvait résoudre vraiment le problème économique et, encore moins, celui de la croissance démographique. Dans ces paroisses, l'augmentation de la mortalité résulte de l'émigration et du vieillissement de la population.

Prises dans leur ensemble, les conditions économiques peuvent favoriser une forte natalité, influer sur le mouvement des mariages et affecter les taux de mortalité. A elles seules, elles ne fournissent pas une explication complète. Les systèmes de valeurs sont aussi en cause. Là où elles agissent puissamment, c'est au niveau de la diversification des occupations qui relève aussi des arrières-plans institutionnels. Nous avons aussi vu que la pression démographique et la concentration des terres peuvent contribuer à la multiplication des effectifs non spécialisés. Il reste cependant que la structure des occupations en 1831 exprime les progrès de la mise en valeur des ressources du milieu. Il suffit de compter le nombre de chasseurs et de voyageurs professionnels pour comprendre que l'économie des pelleteries est révolue. Il est certain cependant que celle-ci avait eu certaines conséquences dans les campagnes où se recrutait une partie de la main-d'œuvre. Il semble cependant que l'ouverture d'un marché extérieur pour le blé canadien avait constitué, durant la dernière partie du XVIII ${ }^{\mathrm{e}}$ siècle, le principal facteur de diversification dans la société rurale. En ce sens, les pêcheries jouent aussi un rôle. Puis, au début du XIX ${ }^{\mathrm{e}}$ siècle, l'expansion rapide du commerce du bois et celle du trafic maritime sont d'importants agents de transformation. L'économie rurale entretient donc, malgré des attitudes de repli évidentes, des rapports avec celle des villes. Disons qu'elle ne peut échapper, même avec le déclin du nombre des vendeurs de blé, la multiplication des consommateurs de froment et le recours à des productions locales, à l'emprise de la ville.

La croissance des effectifs non agricoles dans les campagnes a d'importantes répercussions. Le rôle du marchand en tant qu'artisan du changement économique est évident. Il est aussi l'un des principaux bénéficiaires de l'expansion du marché 
local et des contacts avec la ville. D'autre part les gens de commerce, les professionnels, les artisans prospères et les gros cultivateurs sont davantage en mesure d'envoyer leurs enfants dans les collèges ou de les placer en apprentissage à la ville ou dans les centres régionaux plus actifs. Mais tous les fils des éléments non-agricoles ne sont pas appelés à la promotion sociale et ils n'ont pas comme seule mission d'assurer la continuité. Une forte proportion d'entre eux doit retourner à la terre ou, lorsque celle-ci fait défaut, est forcée d'aller grossir les effectifs des journaliers. Elle fait alors partie du groupe des candidats à l'émigration. Les difficultés économiques, en particulier dans le secteur agricole, limitent les possibilités de diversification et contribuent à l'encombrement de certaines occupations. La situation telle qu'elle se dessine en 1831 traduit une sorte de stagnation. La faiblesse de l'industrie dans les villes et l'immigration en provenance des îles britanniques empêchent les surplus démographiques des campagnes d'aller vers la ville, si ce n'est sur une base saisonnière. Depuis longtemps, ils se dirigent pour une part vers les paroisses rurales du district de Montréal où ils accentuent la surpopulation. Ils empruntent aussi, peut-être par étapes, la route des Etats-Unis. La diversité des ressources et l'émigration relâchent jusqu'à un certain point la pression démographique et réduisent les tensions sociales dans le district de Québec. Cette recherche n'est qu'une amorce d'enquêtes plus poussées. 